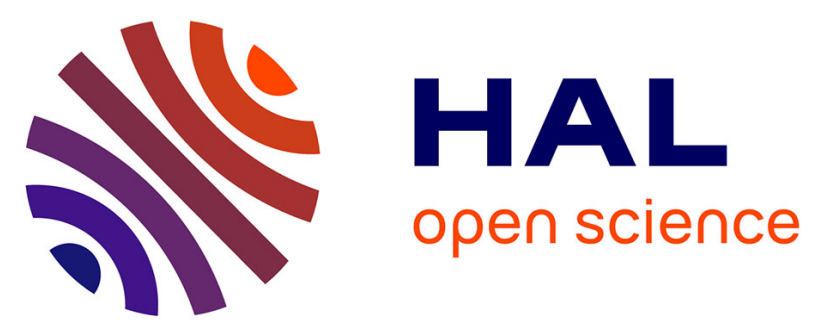

\title{
Maternal and personal information mediates the use of social cues about predation risk
}

Laurane Winandy, Lucie Di Gesu, Marion Lemoine, Staffan Jacob, José

Martin, Christine Ducamp, Michèle Huet, Delphine Legrand, Julien Cote

\section{- To cite this version:}

Laurane Winandy, Lucie Di Gesu, Marion Lemoine, Staffan Jacob, José Martin, et al.. Maternal and personal information mediates the use of social cues about predation risk. Behavioral Ecology, 2021, 32 (3), pp.518-528. 10.1093/beheco/araa151 . hal-03233381

\section{HAL Id: hal-03233381 \\ https://hal.science/hal-03233381}

Submitted on 29 Sep 2021

HAL is a multi-disciplinary open access archive for the deposit and dissemination of scientific research documents, whether they are published or not. The documents may come from teaching and research institutions in France or abroad, or from public or private research centers.
L'archive ouverte pluridisciplinaire HAL, est destinée au dépôt et à la diffusion de documents scientifiques de niveau recherche, publiés ou non, émanant des établissements d'enseignement et de recherche français ou étrangers, des laboratoires publics ou privés. 


\section{Maternal and personal information mediates the use of social cues}

\section{2 about predation risk}

3 Laurane Winandy ${ }^{1,2}$, Lucie Di Gesu ${ }^{1}$, Marion Lemoine ${ }^{1}$, Staffan Jacob ${ }^{2}$, José Martin ${ }^{3}$,

4 Christine Ducamp ${ }^{1}$, Michèle Huet ${ }^{2}$, Delphine Legrand ${ }^{2}$ and Julien Cote ${ }^{1}$

$5 \quad{ }^{1}$ CNRS, Université Toulouse III Paul Sabatier, ENFA; UMR5174 EDB (Laboratoire

6 Évolution \& Diversité Biologique), Toulouse, France

${ }^{2}$ CNRS, UMR5321, Station d'Écologie Théorique et Expérimentale, Moulis, France

${ }^{3}$ Department of Evolutionary Ecology, Museo Nacional de Ciencias Naturales, CSIC, José Gutiérrez Abascal 2, 28006, Madrid, Spain.

\section{FUNDINGS}

This work was carried out at the Station d'Ecologie Theorique et Experimentale (Centre National de la Recherche Scientifique (CNRS) UMR 5321) and the Laboratoire Evolution et Diversité Biologique (CNRS, Université Paul Sabatier, IRD, UMR 5174), which are supported by the Laboratoires d'Excellence TULIP (ANR-10-LABX-41) and CEBA (ANR10-LABX-25-01). Laurane Winandy was supported by the Fyssen Foundation Post-Doctoral Fellowship and Julien Cote by an ANR-12-JSV7-0004-01. This work was supported by an 'Investissements d'avenir' programme from the Agence Nationale de la recherche number ANR-11-INBS-0001AnaEE-Services. Analyses reported in this article can be reproduced using the data provided by Author (Winandy L, Cote J. 2020). 


\section{Abstract}

Organisms can gain information about predation risks from their parents, their own personal experience and their conspecifics, and adjust their behavior to alleviate these risks. These different sources of information can, however, provide conflicting information due to spatial and temporal variation of the environment. This raises the question of how these cues are integrated to produce adaptive antipredator behavior. We investigated how common lizards (Zootoca vivipara) adjust the use of conspecifics cues about predation risk depending on whether the information is maternally- or personally-acquired. We experimentally manipulated the presence of predator scent in gestating mothers and their offspring in a fullcrossed design. We then tested the consequences for social information use by monitoring offspring social response to conspecifics previously exposed to predator cues or not. Lizards were more attracted to the scent of conspecifics having experienced predation cues when they had themselves no personal information about predation risk. In contrast, they were more repulsed by conspecific scent when they had personally obtained information about predation risk. However, the addition of maternal information about predation risk cancelled out this interactive effect between personal and social information: lizards were slightly more attracted to conspecific scent when these two sources of information about predation risk were in agreement. A chemical analysis of lizard scent revealed that exposure to predator cues modified the chemical composition of lizard scents, a change that might underlie lizards' use of social information. Our results highlight the importance of considering multiple sources of information while studying anti-predator defenses.

\section{Key words}

Anti-predator behavior, conspecific attraction, disturbance cues, inadvertent social information, maternal stress, private information, transgenerational plasticity 


\section{INTRODUCTION}

Prey frequently respond to the risk of predation via plastic physiological, morphological and/or behavioural changes, with strong implications for individual fitness (Lima 2002; Benard 2004). The most common antipredator behaviours include active escape, reduction of activity, shelter use or grouping behaviour (Krause et al. 2002; Lima 2002; Winandy et al. 2015). Although these behavioural defences are expected to enhance survival, they may also be costly (Lind and Cresswell 2005). For example, reducing activity or increasing the time spent in refuge alleviates the risk of being detected by a predator but also decreases foraging and mating opportunities. Consequently, individuals should experience energy allocation trade-offs between predator avoidance and other essential activities (Lima 1998). Organisms should therefore benefit from obtaining information about predation risk to maximize their benefit-cost ratio of antipredator behaviors.

Prey may rely on a variety of cues from different sources to assess predation risk. Throughout their life, individuals gain information by personal experience, which implies observation, detection and/or direct non-lethal encounter with predators. Individuals can also gain information from parental cues carried over to the next generation (i.e., transgenerational effects). In particular, if mothers have reliable information about the risk of predation that their offspring are likely to encounter in the future, they can shape their offsprings' phenotype to be better defended against predator (Sheriff and Love 2013; Sheriff et al. 2017). For example, offspring produced by mother exposed to predation risk can exhibit morphological defense (e.g. the helmet morph in Daphnia, Agrawal et al. 1999; the greater wing length in great tits, Coslovsky and Richner 2011); an increase growth rate (Donelan and Trussell 2018a; Donelan and Trussell 2018b); more active and bold personalities (Donelan and Trussell 2015)). Such adaptive maternal stress may occur for example when the circulating maternal glucocorticoid hormones during pregnancy is linked to a relevant ecological stressor 
leading to programing the stress axis of offspring in order to prepare them to cope, reproduce and survive in an environment where the ecological stressor is frequently encountered (Love and William 2008; Sheriff et al. 2010; Love et al. 2013; Sheriff et al. 2017; Potticary and Duckworth 2020). For example, in common lizards, high maternal levels of corticosterone influence juvenile activity, basking and dispersal behavior (Belliure et al. 2004; Meylan et al. 2002; Meylan and Clobert 2005).

While personal and parental information are well-studied for predation risk, organisms can also gather information that is socially transmitted by conspecifics (i.e., social information; Danchin et al. 2004; Dall et al. 2005; Blanchet et al. 2010). Social information can either rely on intentionally produced signals (e.g., alarm calls), or on behavioral and chemical cues produced inadvertently by individuals (Danchin et al. 2004).

In natural populations, the sources of information can contradict each other because of the spatial and temporal variation of environmental conditions. Organisms therefore have to decide on whether to respond to the information received. The reliability of some sources over others usually depends on the predictive accuracy of cues informing about the current and future environments. For example, social information being generally recognized as less reliable than personal information, individuals might favor personal information over social when sources are in conflict. Alternatively, because predation risk can fluctuate in time and space, individuals might trust conspecifics information about a threat over their own information about safety (Crane and Ferrari 2015). A general assumption is that the addition of consistent sources of information should increase the predictive accuracy of information, and result in a linear relationship between the number of coherent sources and the adaptiveness of the phenotype (Leimar and McNamara 2015). Yet, accumulating coherent sources of information may not be required when a single source of information is sufficient to go beyond a threshold and elicit a response (Buoro et al. 2012). This could particularly be 
the case when dealing with life threatening information such as the presence of predators; prey should overestimate the degree of risk (Johnson et al. 2013) and respond to predatory cues even if they come from only a single source (Blanchet et al. 2010). While theoretical studies provided several models of cues integration (Stamps and Krishnan 2014; Dall et al. 2015; Leimar and McNamara 2015), experimental studies that examine how prey integrates information from multiple sources in order to make behavioural decisions are still rare (Beaty et al. 2016; Donelan and Trussell 2018a; Stein et al. 2018). A more general evolutionary understanding of information use in anti-predator defense requires that we understand how individuals integrate transgenerational cues informing them about the past environment with immediate environmental cues (personally- or socially-acquired) to produce adaptive phenotypes (Leimar and McNamara 2015; McNamara et al. 2016).

Here, we experimentally tested whether personal and transgenerational information influence the use of social information about predation risk in the common lizard Zootoca vivipara, a small lacertid widespread in Eurasia. To do so, we used a full-crossed design in which maternal information was manipulated by maintaining gestating females with or without olfactory cues from a predator (snake), and personal information was manipulated by raising the offspring from these females with or without predator cues. We manipulated predation risk with olfactory cues rather than with actual predators because lizards are able to innately detect chemicals left on the substrate by a snake predator (Van Damme et al. 1995). Further, snake cues gained personally or through maternal effects effectively elicit lizard antipredator responses including morphological (e.g., tail length), behavioral (e.g., activity, basking) and life history strategies (e.g., dispersal, mate choice) (Van Damme et al. 1995; Downes and Shine 1999; Bestion et al. 2014; Teyssier et al. 2014; Ortega et al. 2017). We then assessed the use of social information about predation risk through the level of attraction to conspecific scents. This assay has been routinely used in common lizards to assess 
individual attraction towards conspecific cues depending on cues such as donors' relatedness (Léna et al. 1998; Léna et al. 2000), past experience of competition (Aragón et al. 2006; Aragon et al. 2006), and more generally the individual social strategy with respect to population density (Cote and Clobert 2007; Cote et al. 2008; Le Galliard et al. 2015; Mell et al. 2016). We used the scent of conspecifics either previously exposed to predator cues or not, and tested the attraction to these conspecific cues (i.e., sociability) of focal individuals at the subadult stage (i.e., one year old). To go deeper into the molecular mechanisms responsible for social information, we tested whether exposure to predator cues modified lizard scent. When an organism is disturbed or stressed, but not captured by a predator, it can indeed release chemical cues (Chivers and Smith 1998), as shown in lacertids (Aragón et al. 2008). These modified scents can act as disturbance cues warning nearby conspecifics of the risk of predation (Chivers et al. 2012; Bairos- Novak et al. 2019; Bairos- Novak et al. 2019).

While previous studies have shown that common lizards use social information to make behavioral decisions (e.g., Aragon 2006; Cote \& Clobert, 2007, 2010), it is unknown how maternal and personal information may modulate the use of conspecific cues about predation risks. We could broadly expect that either all sources of information (i.e., maternally, personally or socially-acquired) influence lizard's responses in an additive way, or that more reliable sources of information elicit a threshold response. Since personal and maternal information are usually more reliable than social information, we predict that social information about predation risk would matter more when maternal and personal cues about predation risk are lacking, or when they provide conflicting information.

\section{MATERIALS AND METHODS}

\section{Maternal and personal information}

We manipulated the perceived predation risk by exposing lizards to predator cues over two generations. This experiment was approved by the ethical committee and the French 
government: APAFIS\#19524-2019022816109633 v2. Fifty-four gestating females were captured during spring 2014 from 4 natural populations in the Cévennes mountains (Lozère, France, Licence no.2010-189-16 DREAL), and brought back to the lab in the CNRS Station d'Ecologie Théorique et Expérimentale (Moulis, France). While we did not know the previous experience of females with predators, snakes were observed in only 2 of the 4 populations during the last 20 years of monitoring (pers. comm. Jean Clobert). We therefore equally distributed females from each population and from populations with and without observed snakes between the two treatments (populations with snakes: 16 females and their 44 juveniles in the predation risk treatment and 16 females and 42 juveniles in the control treatment, populations without snakes: 10 females and 24 juveniles in the predation risk treatment and 12 females and 27 juveniles in the control treatment). We maintained females in 24 outdoor tanks (1100 L; diameter: $1.70 \mathrm{~m}, 2$ females in each tank, except 1 tank of each treatment with 3 females) containing $20 \mathrm{~cm}$ of soil litter, dense vegetation, one dish for water and a weekly addition of crickets, Acheta domestica. We provided refuges by adding several $5 \mathrm{cl}$ falcon tube in the litter, three half flower pots and two perforated bricks. A basking area was available in the center of the tanks, using a few rocks and three logs. These housing conditions were highly suitable for lizards, as shown in previous experiments (Bestion et al. 2014; Teyssier et al. 2014). Gestation usually lasts 2-3 months depending on air temperature.

During the last month of gestation, we manipulated maternal information by exposing the females to predator or control scent (see below for the detail description of the procedure). Before the first parturition, females were brought to the lab in $35 \times 18$ x $22 \mathrm{~cm}$ individual terraria filled with $5 \mathrm{~cm}$ substrate, providing two shelters (on and under the ground) and a water bowl. A light bulb $(25 \mathrm{~W})$ and an UV lamp provided respectively a heat source and light from 9 AM to noon and from 2 PM to 5 PM. In addition, each terraria were water sprayed three times a day. Food was provided daily with two crickets per lizard. Since the lizard populations used in this study are viviparous, we separated all newborns from their 
mother just after parturition. In total, we raised 137 juveniles that we marked by toe clipping (approved by the ethical committee and the French government: APAFIS\#15897$2018070615164391 \mathrm{v} 3$ ) and sexed by counting the number of ventral scales (Massot et al. 1992). Each clutch, whose mother was either exposed or unexposed to predator scents, was equally split between the two treatments for personal information. Using this full-crossed design (Figure 1), we exposed two generations of lizards to predator cues: offspring unexposed from mother unexposed (P-M-, n=39; $\mathrm{P}$ for personal information and $\mathrm{M}$ for maternal information), offspring unexposed from mother exposed (P-M+, n=36), offspring exposed from mother unexposed $(\mathrm{P}+\mathrm{M}-, \mathrm{n}=30)$ and offspring exposed from mother exposed $(\mathrm{P}+\mathrm{M}+, \mathrm{n}=32)$. Offspring were raised in 24 outdoor tanks (in the same maintenance conditions as described before). We randomly distributed the juveniles into 12 tanks of a control treatment and 12 tanks of a predation treatment (5 to 7 individuals in each tank), checking there were no difference in body size or body mass between treatments (body size: $t$ $=-1.127, P=0.261$; body mass: $t=-0.344, P=0.731)$. The density and sex-ratio were similar between treatments (generalized linear model with a Poisson distribution and a $\log$ link, number of lizards: $\mathrm{P}-=6.00 \pm 0.21, \mathrm{P}+=5.92 \pm 0.19, P=0.93$; number of females (with number of lizards as a covariate): $\mathrm{P}-=0.55 \pm 0.02, \mathrm{P}+=0.52 \pm 0.02, P=0.78)$. Offspring personal exposure was manipulated twice: just after birth at the juvenile stage (in summer 2014) and one year later at the subadult stage (in summer 2015).

\section{Predation risk treatments}

We used the cues of a natural predator the green whip snake, Hierophis viridiflavus. Common lizards have an innate recognition of snakes as a threat and their highly developed tongue-vomeronasal system allows them to detect chemicals that are left on the substrate by the snake predator. Lizard responses to snake scents strongly decreases the chance of capture 
(Downes 2002). Common lizards live in dense vegetation and their population density is much higher than that of snakes. Direct encounters with snake are therefore rare but highly lethal. This innate aversion of lizard to predatory scents is thus subjected to minor ontogenetic changes and is stable over long periods of time without an encounter with a snake (Van Damme et al. 1995; Bestion et al. 2014).

We kept the green whip snake in a terrarium providing a water bowl, a shelter and a light bulb for basking. To collect snake odours, we placed calcite tiles $(3 \times 3 \times 0.6 \mathrm{~cm})$ in the snake cage for three days and gently rubbed, using rubber gloves, on the snake body before use. We used identical tiles (i.e. blank tiles), kept in a separate room, for the control treatment without snake scent. We placed fives tiles in each outdoor home tank, blank tiles for the control tanks and tiles with cues for the predation tanks. Every three days for four weeks, we exchanged old tiles of both treatments for new ones before olfactory cues could vanish in the outdoor tanks. This same predator exposure protocol was used for all sources of information: the maternal exposure in Mai 2014, the offspring exposure in August 2014 at juvenile stage and in August 2015 at subadult stage. While we did not use any physical encounters to maintain the potential anti-predatory response, one month of exposure to predatory cues is not enough to trigger habituation (Downes 2001; Downes 2002). Moreover, we did not use the scent of the same snake for exposure at the juvenile and subadult stages. This scent novelty that should maintain lizard responsiveness. Previous studies show that both within and between-generation responses are induced by predator olfactory cues manipulated over a month (Shine and Downes 1999; Bestion et al. 2014), which makes this procedure, along with ethical considerations, the most suitable option.

\section{Social information and attraction to conspecific cues}


Social information about predation was provided after the second exposure to predation cues at the subadult stage (in late summer 2015). We assessed individual social response to the cues of conspecifics that were previously exposed to predator cues $(\mathrm{S}+)$ or not (S-). Following the full crossed-design experiment (Figure 1), half of the lizards from each treatment (i.e., $\mathrm{P}-\mathrm{M}-, \mathrm{P}-\mathrm{M}+, \mathrm{P}+\mathrm{M}-$ and $\mathrm{P}+\mathrm{M}+$ ) were exposed to $\mathrm{S}+$ and the other half were exposed to S-. To do so, we collected pooled scents from the lizards maintained in each of the 24 tanks just after the predation treatment at the subadult stage (August 2015). These 24 groups (12 from the control treatment and 12 from the predation treatment) were housed separately in large terraria $(35 \times 18 \times 22 \mathrm{~cm})$ covered by paper towel during one week. Twenty-four pieces of paper containing the feces of each group were then used during the social attraction test. Each tested lizard was exposed to one of the 24 different scents, always avoiding the scent of their own group to exclude the possibility that lizards were exposed to their own feces or to feces from a conspecific that they already knew. Lizards were cleaned using an antiparasite solution (Cfrontline) before being released in the terraria and could therefore not bear predator cues from tiles on them. We collected the papers devoid of conspecific scent from vacant terraria maintained in the same conditions as our inhabited terraria.

We tested social attraction with a choice assay between two compartments with or without scents of conspecifics. This type of assay is commonly used in common lizards and other lizard species to quantify individuals' social strategies (Cote and Clobert 2007; Cote et al. 2008; Rodríguez-Prieto et al. 2011; Teyssier et al. 2014; Le Galliard et al. 2015; Mell et al. 2016). In reptiles, lizards' scents convey various types of information about the donor (Martín \& Lopez, 2010, 2014). Therefore, the assay allowed us to measure attraction to conspecific cues depending on donors' characteristics (i.e., social information, Léna et al. 1998; Léna et al. 2000; Aragón et al. 2006). We used glass terraria $(34 \times 17 \times 25 \mathrm{~cm})$ divided in three compartments: a shelter without conspecific scents was put at one end of the terrarium and a 
shelter with conspecific scents was put at the other end of the terrarium. We placed each lizard in the central compartment (devoid of shelter and scent) for four hours and we started the assay by removing the walls separating the compartments. After $10 \mathrm{~min}$ of acclimation to the two shelters, we recorded for another $10 \mathrm{~min}$ the time spent in each compartment and on/under each shelter to estimate social tendency. Video were analyzed using "The Observer" software, allowing the exact measurement of the time in each location. The observer was blind to the treatment of individuals.

\section{Analysis of scent chemical composition}

We analyzed the chemical composition of scent samples collected in the 24 terraria in the same manner as those used for the social attraction test (12 from the control treatment and 12 from the predation treatment). This means that for each group, the sample was made of several pieces of paper towel with feces and was composed of a mix of individual scents. We collected feces instead of femoral secretions because feces are also commonly used in lacertid lizard to simulate olfactory responses (Aragón et al. 2000, López et al. 1998, Moreira et al. 2008) and chemical communication based on femoral secretions is relatively less important in this species (Gabirot et al. 2008). Samples were collected using surgical pliers cleaned with alcohol and rinsed with sterile water between each population. Samples of paper towel and soil from vacant terraria were also collected as controls. Samples were disposed in glass vials and kept at $-80^{\circ} \mathrm{C}$ until analyses.

Chemical compounds were analyzed using solid phase microextraction (SPME) with a Stableflex fiber (50/30 $\mu \mathrm{m}$ DVB/CAR/PDMS, Supelco, Sigma-Aldrich, Bellefonte, PA, USA). Samples were placed at $50^{\circ} \mathrm{C}$ for $20 \mathrm{~min}$, and the fiber was then exposed to the headspace of the glass vials (without touching the towel) for 20min. Absorbed chemicals were then analyzed on a mass spectrometer quadrupole detector (ISQ QD) coupled to a Trace 1300 gas chromatography (Thermo Fisher Scientific Inc) with a capillary column (Restek RTX-5MS 30 
$\mathrm{m} \times 0.25 \mathrm{~mm}, 0.25 \mathrm{~lm}$ film thickness, 5\% diphenyl and 95\% dimethylpolysiloxane) and a splitless injector $\left(300{ }^{\circ} \mathrm{C}\right)$. Ionization was performed by electron impact $(70 \mathrm{eV}$, source temperature $\left.250{ }^{\circ} \mathrm{C}\right)$. Helium was the carrier gas $(1.2 \mathrm{ml} / \mathrm{min})$. The oven temperature was initiated at $40{ }^{\circ} \mathrm{C}$ for $1 \mathrm{~min}$, and then programmed to increase $10{ }^{\circ} \mathrm{C} / \mathrm{min}$ to $300{ }^{\circ} \mathrm{C}$ and held at $300^{\circ} \mathrm{C}$ for $5 \mathrm{~min}$. The scan range of the mass spectrometer was 60 to $500 \mathrm{~m} / \mathrm{z}$. Blanks were regularly interspersed throughout the sample analyses. After removing the compounds found in paper towel and soil (i.e., control sample without feces), we obtained 62 different peaks (i.e., compounds). The relative abundance of compound refers to the relative areas of the selected peaks that were restandardized to $100 \%$. Tentative compound identification was performed based on mass spectral fragmentation patterns and comparison with the NIST mass spectral library using Xcalibur software.

\section{Statistical analysis}

To summarize the data collected during the social attraction test, we performed a Principal Component Analysis (PCA) using the time spent in each compartment (i.e., with or without conspecific scents, excluding the central compartment) and the time spent on, and under each shelter. These data were scaled to unit variance before the analysis. The PC1 axis explained $39 \%$ of the variance and had an eigenvalue of 2.32 . It was positively correlated to behaviors in the compartment without scent (PC loadings: 0.94 for the total time spent in the compartment without scent and 0.6 for the time spent under the shelter) and negatively correlated to behaviors in the compartment with conspecific scent (PC loadings: -0.92 for the total time spend in the compartment with scent and -0.44 for the time spend under the shelter). To make interpretation easier, we multiplied scores by -1 . Higher scores on the PC1 axis then corresponded to higher attraction to conspecific scent (i.e., higher sociability). 
Afterward, we used linear mixed models to assess the effect of maternal, personal and social information about predation (single effects and interactions between these three factors) on social attraction. We added sex and body size (snout-vent length) as covariates as they can influence sociability (Michelangeli, Chapple, \& Wong, 2016), and mother identity and tank group as random intercepts. Sex and body size did not affect the use of conspecific cues $(P>$ 0.11 for simple effects and interactions with the three sources of information) and were therefore removed from the model. We then used likelihood ratio tests to estimate the significance of factors and interactions in the model and provided summary of parameter estimates and confidence interval (95\%). To test the additive effects of information sources about predation risk on social attraction, we ran a linear regression by scoring the number of sources as follow: 0 when there were neither personal nor conspecific cues about risk, 1 when there were either a personal information or conspecific cue about risk and 2 when there were both personal information or conspecific cue about risk. Compliance with requirement of the fitted linear model were checked using Shapiro-Wilk normality test on the model residuals assessing social attraction $(\mathrm{W}=0.988, P=0.29)$.

We assessed the effect of predation risk on lizard chemical profile. We first analyzed the number of compounds present in each of the 24 chemical profiles (each tank) using a GLM assuming a Poisson error distribution and a log link. We then perform analysis on the occurrences (presence/absence) of chemical compounds that convey threshold information. We identified differences in the occurrence of compounds between treatments using a discriminant analysis (LDA) effect size (LEfSe) on the 62 initial compounds using the Galaxy platform (http://huttenhower.sph.harvard.edu/galaxy/) with a $0.05 \mathrm{p}$-value threshold and a LDA score $>2$ (supplementary table 1). As a cross-validation, we also ran a similarity percentage analysis on the occurrence of the 62 compounds (supplementary table 2) and considered the compounds identified as different in both LDA and similarity analysis as important. We then summarized the occurrence of the 62 compounds using a LDA and a 
MCA (i.e. Multiple Correspondence Analysis). The two methods are complementary as the LDA summarizes differences in chemical profiles between treatments in a single variable and the MCA summarize chemical profiles regardless of the treatments. The contribution of each compound to the first axis of a LDA was examined using linear models with LDA axis as a dependent variable and the occurrence of the compound as an explanatory variable (supplementary table 3). For the MCA, we kept the first two axes (i.e., MC1 and MC2) as they explained respectively $12.62 \%$ and $10.80 \%$ of the variance and had an eigenvalue of 0.12 and 0.11 , respectively. The contribution (in \%) of each compound to the first two axis of the MCA is in Supplementary table 4.

We used the occurrences above rather than the relative abundances because a high proportion of relative abundances were equal to 0 which complicated the transformation needed for the PCA and LDA. However, the analysis using relative abundances largely supported the results based on the occurrence data (see supplementary material). The LDA analysis using galaxy identified the same compounds (supplementary table 5) and the LDA axis on abundances was highly correlated to the LDA axis on occurrences (Estimate: 0.99, $\left.\mathrm{SE}=0.04, \mathrm{R}^{2}=0.96, P<0.0001\right)$. The contribution of each compound to the first axis of a LDA was examined using Spearman rank correlations (supplementary table 6). For the PCA, we kept the first two axes (i.e., PC1 and PC2) as they explained respectively $13.97 \%$ and $11.36 \%$ of the variance and had an eigenvalue of 8.66 and 7.04 , respectively. The component loadings of the relative abundance of chemical compounds can be found in supplementary table 7.

A final post-hoc analysis investigated whether the identified differences in chemical profiles between exposed and unexposed donors are responsible for the effect of predation risk on the use of conspecific cues. We compared effects sizes of the predation risk treatment of cues donors (i.e. the social information as reported in Table 1) and of the chemical profiles 
on social attraction. Similar or higher effect sizes would suggest that the descriptor may convey the social information about predation risk, while lower effect sizes would suggest additional unidentified information carriers. To do so, we ran the same linear model with maternal, personal and social treatments on lizard sociability (as in Table 1), but replacing the social information treatment by the descriptors of the cues used for the social information assay (supplementary table 8). The descriptors were the number of compounds, the two MCA axes, the LDA axis and the occurrence of compounds that differed between predation and control treatment. We extracted effect sizes (standardized beta coefficients) and compared it to the effect for the predation risk treatments of cues donors in interaction with maternal and personal treatments. Note that caution about conclusion should be exercised, as only an experimental manipulation of chemical profiles would permit us to test directly the role of chemical profile. Finally, we performed the same post-hoc analysis using the descriptors of compound abundance: the LDA axis of the abundance, the two PCA axis and the abundance of compounds that differed between predation and control treatment (supplementary table 9). We provided p-values in supplementary tables 8 and 9 for information purposes. Only the effects sizes should be interpreted, as they are not influenced by the post-hoc multiple testing. Analyses were performed in R 3.5.1 (www.r-project.org) using FactoMinR (Lê et al. 2008), ggplot2 (Wickham et al. 2016), lme4 (Bates et al. 2007), sjstats (Lüdecke and Lüdecke 2017), MASS (Ripley et al. 2013), and vegan (Oksanen et al. 2007) packages.

\section{RESULTS}

\section{Effect of sources of information on sociability}

Personal and maternal information interacted to shape the use of social information about predation risk (Table 1). We found a significant interaction between personal and social information on lizards' sociability, but only when mothers were not exposed to predator cues (Table 2, Figure 2a). In this case, lizards with personal information about predation risk were 
repulsed by the scent of conspecifics exposed to predator cues $\left(\chi_{1}^{2}=50.579, P<0.001\right)$, while naïve lizards tended to be attracted by these conspecifics scents $\left(\chi^{2}{ }_{1}=3.147, P=\right.$ 0.076). Maternal exposure to predation risk canceled out this interaction between personal and social information (Table 2): sociability tended to increase with the number of sources of information about risk (Estimates $=0.442, \mathrm{SE}=0.237, \chi^{2}{ }_{1}=3.478, P=0.062$; Table 2, Figure 2b).

\section{Effect of predation risk on conspecific scent}

The exposure of individuals to predator cues significantly decreased the number of chemical compounds forming lizard scents $\left(\chi_{1}^{2}=7.394, P=0.007\right.$, mean \pm SE, $S+: 16.8 \pm 1.2$ and S-: $12.6 \pm 1.1$ ). The LDA effect size analysis showed that two compounds substantially differed between the profiles of exposed and unexposed lizards (supplementary table 1), which is also confirmed by the similarity percentage analysis (Supplementary Table 2). Other compounds were also identified from the correlations with the LDA axis (Supplementary Table 3) and the similarity percentage analysis (Supplementary Table 2), but it is likely they had a weaker role in the chemical differentiation. The predation treatments had a significant effect on the LDA axis $\left(\mathrm{F}_{1,22}=106.1, P<0.001\right.$, mean $\pm \mathrm{SE}, \mathrm{P}+:-1.251 \pm 0.857$ and $\mathrm{P}-:$ : $\left.1.751 \pm 0.386\right)$, but had no effects on the two MCA axes $\left(\mathrm{MC} 1: \mathrm{F}_{1,22}=1.276, P=0.271\right.$ and $\mathrm{MC} 2: \mathrm{F}_{1,22}=0.902, P=$ 0.353). The tentative identification of chemical compounds indicated that the two main compounds, Compound_1 (i.e. X154) and Compound_2 (i.e. X167), may be respectively a derivative of Napthalenol and an unsaturated alcohol.

We then investigated whether the descriptors of donors' cues could explain the effect of predation risk of conspecific donors by comparing effect sizes. The effect size of the interaction between personal, maternal and social information is similar to the effect size of the interaction using the LDA first axis, and more particularly using the occurrence of Compound_1 and Compound_2 instead of the social information treatment (Supplementary 
Table 8, Figure 3).

Overall, the various analyses of the relative abundance of the chemical compounds showed very similar results to the analysis based on their occurrence. Indeed the LDA effect size analysis highlighted the same two compounds (supplementary table 5, supplementary table 6). The post-hoc analyses comparing effect sizes showed that the effect size of the interaction between personal, maternal and social information is similar or slightly lower than the effect size of the interaction using the PC2 and the abundance of Comp_1 and Comp_2 instead of the social information treatment (Supplementary Table 9, Supplementary figure 1).

\section{DISCUSSION}

We assessed how personally- and maternally-acquired information altered lizards' responses to conspecific cues. We found that personal and maternal information interacted to shape lizard responses to conspecific cues about predation risk. The scent of conspecifics exposed to predation risk attracted more focal lizards when they had no personal information about the risk, while it repulsed them when they also had personal knowledge about the risk. Furthermore, we found that maternal information about predation risk cancelled out this interactive effect between personal and social information, with individuals tending to be more social when sources of information about risk added up.

Prey are known to assess the risk of predation when making decisions about how to behave (Lima 2002). Decision making often results in a trade-off between risk and other rewarding activities (e.g., foraging and mating; Kats and Dill 1998). An accurate risk assessment requires reliable information about predation at a given time and location. Such information can be acquired via multi-modal sensory cues including sight, tactile and chemical signals made by conspecifics. In our study, we manipulated the exposure to predation risk using scents of a snake predator because it is known to elicit anti-predator behavior in common lizards through maternal and personal exposure, even one month after 
exposure (Bestion et al. 2014; Teyssier et al. 2014). Such permanent strong defense behavior without any actual encounter with predators can be explained by the low encounter rate between lizards and snakes in the wild, because of the dense vegetation and the comparatively lowest density of predators. It can further be explained by the high probability the a snake is successful in catching a lizard when an actual attack occurs. We further showed that common lizards can use olfactory cues from conspecifics to assess predation risk, while it was already known that they can perceive different donors' characteristics through scents (i.e., relatedness: Léna et al. 1998; past experiences of competition: Aragón et al. 2006; Aragon et al. 2006). Chemical cues released by a conspecific may signal individual stress levels (Douglas III et al. 2018), body condition (Martín and Lopez 2010) or health status (Martín et al. 2007) and lizard species are particularly prone to use such signals to assess mating partners or competitors (reviewed in Mason and Parker 2010). Predation risk usually requires chemicals from injured conspecifics (i.e., alarm cues) to elicit behavioral defense in other conspecifics (Crane and Ferrari 2013). However, prey can also release a chemical signal when detecting a predator (i.e., disturbance cues; Chivers and Smith 1998; Griffin 2004), or have a modified scent after experiencing predation risk, as found in another lacertid lizard species (Aragón et al. 2008).

Individuals may rely on cues intentionally or inadvertently produced by conspecifics, (defined as social information: Danchin et al. 2004; Dall et al. 2005; Blanchet et al. 2010), to cope with limited personal information about challenging environmental conditions. In the context of predation risk, acquiring social cues may be less costly and therefore more adaptive than acquiring the information personally through a direct encounter with a predator (Blanchet et al. 2010). Moreover, no personal information about predation risk can be unreliable because predators circulate in the environments and their actual presence can be highly variable in space and time. A prey may then overestimate the degree of risk (Johnson et al. 2013) and a response to predator cues could be observed even if they came from only a single source (Nesse 2005; Blanchet et al. 2010). However, when an individual eventually 
encounters a predator, social cues may become less relevant and additional cues about risk may even signal an acute increase in predation risk. In absence of maternal cues, we found that social and personal information about risk increase the attraction towards conspecific scents when these information sources are uncoupled, supposedly because grouping may decrease predation risk (Lima and Dill 1990; Krause et al. 2002). Indeed, an increase in sociability is a common antipredator strategy in lizard that allows for collective vigilance (i.e., increased detection of predators, (Downes and Hoefer 2004; Lanham and Bull 2004) and a risk-dilution effect (i.e., a lower probability for a single individual to be captured, Ioannou 2017). However, in the absence of maternal cues, lizard personally-informed about predators avoided the scents of social partners that were also exposed to predator scents. The accumulation of information sources about predator presence, through personal and social information, may indicate a temporally or spatially acute risk of predation. Lizards may therefore avoid the scent of predator-exposed conspecifics because it signals immediate danger, while the scent of unexposed conspecifics is attractive because it might signal safe conditions. The safest strategy could then be to avoid a particular social partner who has recently encountered a predator.

Transgenerational information can strongly influence prior expectations about individuals' risk, and, in turn, the use of social information. We found that the exposure of mothers to predation risk during gestation cancelled out the observed interaction between personal and social information and was replaced by a weak but significant additive effect of information sources affecting lizard social responses. The attraction towards conspecific scents increased gradually with the number of sources of information about predation risk from lizards with only maternal information to lizards personally, socially and maternally informed. Additional cues might increase an individual's confidence in the state of the environment, causing a multiplicative effect on their sociality. A higher level of sociability 
could indeed be an efficient antipredator strategy in a risky environment. While additivity is less expected in discrete traits such as a defensive morphology (McCollum and Van Buskirk 1996; Buoro et al. 2012), it is more likely to occur in gradual behavioral traits. Maternal information signals environmental conditions on a larger temporal scale than does personal information. When maternal and offspring information matches, it signals a persistent risk across generations (Sheriff et al. 2017), which can explain the additive effect of information sources. The environmental/maternal-matching hypothesis states that maternal stress can be adaptive if the maternal and offspring environmental conditions match (Sheriff et al. 2017). In our study, when personal and maternal information about risk matched $(\mathrm{P}+\mathrm{M}+)$, social information was less valuable. Indeed, individuals showed high attraction to conspecific cues whether or not this conspecific was exposed to predation risk, as in a persistent risk of predation, being more sociable could be beneficial. On the contrary, social information had stronger effect when there was no personal and maternal information about risk (P-M-). In this case, individuals were only attracted by social cues of conspecific that had been exposed to predation risk, which mirrors cases where acquiring personal information is costly (Webster and Laland 2008). If social cues were misleading, it would only result in reduced foraging or mating opportunities, while not responding to a relevant danger cue could result in higher mortality risk by predation. Prey might thus benefit from erring on the side of caution (Johnson et al. 2013).

Finally, we also attempted an assessment of the molecular mechanisms responsible for social information by collecting feces samples from groups of lizards exposed and unexposed to predation risk to identify potential changes in their chemical scent profiles. In our study, predators never injured lizards, as we never exposed lizards to actual predators, so there were no compounds released upon injury (i.e., damage-release chemical alarm signals; Chivers et al. 1996). Despite no physical encounter with predators, as in natural populations, the 
exposure to predator cues changed the chemical composition of lizard scents collected from feces. We found fewer chemical compounds in the scent of lizards exposed to predation risk compared to unexposed lizards. Our conservative analysis revealed that two compounds were differently expressed between treatments. The tentative identification of the chemical compounds matches expectations since Lacertid lizards usually have alcohols in their secretions, and alcohols can be detected by conspecifics (Martín and López 2014). This modification of scent profile may have provided chemical cues for risks and triggered the observed behavioral response to conspecific scents. We also ran post-hoc analyses replacing the predation risk treatment of donors' scents by a few descriptors summarizing chemical profiles and compared effect sizes. We expected similar or larger effect sizes if chemical profiles were indeed the mechanisms behind social responses to conspecific scents, and this is what we observed for the two compounds differently expressed between treatments. However, caution should be exercised in interpreting this preliminary investigation of chemical profiles and their influences. In depth chemical analysis and manipulative experiments are required to provide a more precise identification of chemical cues, and to ascertain their influences on lizard's behavior.

\section{CONCLUSION}

Prey generally have incomplete information about their environment and have to rely on other source of information to assess the risk of predation. In our study, the scents of conspecific exposed to predation risk acted as social information shaping behavioral responses. However, when personal and social information conflicted, which is mostly the rule in stochastic environments, decision making can be hampered. Transgenerational information seemed to alleviate the uncertainty about risk when personal and social information mismatched. Transgenerational cues can provide information on a larger temporal scale and influence the prior expectations of individuals about their environment. Moreover, ancestors' experience is 
the first possible source of information an individual can get and, therefore, may have large effects on phenotypic outcomes (Dufty Jr et al. 2002; Fawcett and Frankenhuis 2015; English et al. 2016; Donelan and Trussell 2018a). Maternal exposures to predation cues may adaptively prepare the phenotype of offspring for more stressful environmental conditions (Uller 2008; Sheriff and Love 2013; Sheriff et al. 2017) but also induce changes in the developmental trajectory of offspring, leading to direct or delayed effects on individuals from the embryonic stage to adulthood (Love and Williams 2008; Nettle and Bateson 2015). Here we found that maternal stress affected how offspring used the cues from conspecific later in life. While our study raises interesting perspectives on how animals integrate information from a wide variety of sources to make decisions, we believe additional studies on this and other taxa are required to replicate our results and test the generality of our conclusions. Understanding the complex mechanisms involved in the integration of multiple information sources within and among several generation deserves further attention (Sheriff et al. 2017).

\section{REFERENCES}

Aragón P, López P, Martín J. 2000. Size- dependent chemosensory responses to familiar and unfamiliar conspecific faecal pellets by the Iberian rock- lizard, Lacerta monticola. Ethology, 106(12), 1115-1128.

Aragón P, López P, Martín J. 2008. Increased predation risk modifies lizard scent- mark chemicals. J Exp Zool A Ecol Genet Physiol. 309(7):427-433.

Aragón P, Massot M, Gasparini J, Clobert J. 2006. Socially acquired information from chemical cues in the common lizard, Lacerta vivipara. Anim Behav. 72(5):965-974.

Aragon P, Meylan S, Clobert J. 2006. Dispersal status- dependent response to the social environment in the Common Lizard, Lacerta vivipara. Funct Ecol. 20(5):900-907.

Agrawal AA, Laforsch C, Tollrian R. 1999. Transgenerational induction of defences in animals and plants. Nature. 401(6748): 60-63. 
Bairos- Novak KR, Ferrari MC, Chivers DP. 2019. A novel alarm signal in aquatic prey: Familiar minnows coordinate group defences against predators through chemical disturbance cues. J Anim Ecol.:1281-1290.

Bates D, Sarkar D, Bates MD, Matrix L. 2007. The lme4 package. R package version. 2(1):74.

Beaty LE, Wormington JD, Kensinger BJ, Bayley KN, Goeppner SR, Gustafson KD, Luttbeg B. 2016. Shaped by the past, acting in the present: transgenerational plasticity of anti- predatory traits. Oikos. 125(11):1570-1576.

Belliure J, Meylan S, Clobert J. 2004 Prenatal and postnatal effects of corticosterone on behavior in juveniles of the common lizard, Lacerta vivipara. J Exp Zool Part Comp Exp Biol. 301A: 401-410.

Benard MF. 2004. Predator-induced phenotypic plasticity in organisms with complex life histories. Annu Rev Ecol Evol Syst. 35:651-673.

Bestion E, Teyssier A, Aubret F, Clobert J, Cote J. 2014. Maternal exposure to predator scents: offspring phenotypic adjustment and dispersal. Proc $R$ Soc B. 281(1792):20140701.

Blanchet S, Clobert J, Danchin É. 2010. The role of public information in ecology and conservation: an emphasis on inadvertent social information. Ann N Y Acad Sci. 1195(1):149-168.

Buoro M, Gimenez O, Prévost E. 2012. Assessing adaptive phenotypic plasticity by means of conditional strategies from empirical data: the latent environmental threshold model. Evolution: International Journal of Organic Evolution. 66(4):996-1009.

Chivers DP, Brown GE, Ferrari MC. 2012. The evolution of alarm substances and disturbance cues in aquatic animals. Chemical ecology in aquatic systems:127-139.

Chivers DP, Kiesecker JM, Anderson MT, Wildy EL, Blaustein AR. 1996. Avoidance response of a terrestrial salamander (Ambystoma macrodactylum) to chemical alarm 
cues. J Chem Ecol. 22(9): 1709-1716.

578 Chivers DP, Smith RJF. 1998. Chemical alarm signalling in aquatic predator-prey systems: a review and prospectus. Ecoscience. 5(3):338-352.

580

Coslovsky M, Richner H. 2011. Predation risk affects offspring growth via maternal effects. Funct. Ecol. 25, 878-888.

Cote J, Boudsocq S, Clobert J. 2008. Density, social information, and space use in the common lizard (Lacerta vivipara). Behav Ecol. 19(1):163-168.

Cote J, Clobert J. 2007. Social information and emigration: lessons from immigrants. Ecol lett. 10(5):411-417.

Crane AL, Ferrari MC. 2013. Social learning of predation risk: a review and prospectus. Social learning theory: phylogenetic considerations across animal, plant, and microbial taxa.:53-82.

Crane AL, Ferrari MC. 2015. Minnows trust conspecifics more than themselves when faced with conflicting information about predation risk. Anim Behav. 100:184-190.

Dall SR, Giraldeau L-A, Olsson O, McNamara JM, Stephens DW. 2005. Information and its use by animals in evolutionary ecology. Trends Ecol Evol. 20(4):187-193.

Dall SR, McNamara JM, Leimar O. 2015. Genes as cues: phenotypic integration of genetic and epigenetic information from a Darwinian perspective. Trends Ecol Evol. 30(6):327-333.

Danchin E, Giraldeau L-A, Valone TJ, Wagner RH. 2004. Public information: from nosy neighbors to cultural evolution. Science. 305(5683):487-491.

Donelan SC, Trussell GC. 2015. Parental effects enhance risk tolerance and performance in offspring. Ecology. 96(8):2049-2055.

Donelan SC, Trussell GC. 2018a. Parental and embryonic experiences with predation risk affect prey offspring behaviour and performance. Proc R Soc B. 285(1874):20180034.

Donelan SC, Trussell GC. 2018b. Synergistic effects of parental and embryonic exposure to 
predation risk on prey offspring size at emergence. Ecology. 99(1):68-78.

604

605

606

607

608

609

610

611

612

613

614

615

616

617

618

619

620

621

622

623

624

625

626

627

628

Douglas III HD, Kitaysky AS, Kitaiskaia EV. 2018. Odor is linked to adrenocortical function and male ornament size in a colonial seabird. Behav Ecol. 29(3):736-744.

Downes S. 2001. Trading heat and food for safety: costs of predator avoidance in a lizard. Ecology. 82(10):2870-2881.

Downes S, Hoefer AM. 2004. Antipredatory behaviour in lizards: interactions between group size and predation risk. Anim Behav. 67(3):485-492.

Downes SJ. 2002. Does responsiveness to predator scents affect lizard survivorship? Behav Ecol Sociobiol. 52(1):38-42.

Downes SJ, Shine R. 1999. Do incubation-induced changes in a lizard's phenotype influence its vulnerability to predators? Oecologia. 120(1):9-18.

Dufty Jr AM, Clobert J, Møller AP. 2002. Hormones, developmental plasticity and adaptation. Trends Ecol Evol. 17(4):190-196.

English S, Fawcett TW, Higginson AD, Trimmer PC, Uller T. 2016. Adaptive use of information during growth can explain long-term effects of early life experiences. The Am Nat. 187(5):620-632.

Fawcett TW, Frankenhuis WE. 2015. Adaptive explanations for sensitive windows in development. Front in Zool. 12(S1):S3.

Gabirot M, Lopez P, Martin J, De Fraipont M, Heulin B, Sinervo B, Clobert J. 2008.

Chemical composition of femoral secretions of oviparous and viviparous types of male common lizards Lacerta vivipara. Biochem Syst Ecol. 36(7): 539-544.

Griffin A. 2004. Social learning about predators: a review and prospectus. Anim Learn Behav. 32(1):131-140.

Ioannou C. 2017. Grouping and predation. Encyclopedia of evolutionary psychological science.:1-6.

Johnson DD, Blumstein DT, Fowler JH, Haselton MG. 2013. The evolution of error: Error 

management, cognitive constraints, and adaptive decision-making biases. Trends Ecol Evol. 28(8):474-481.

Kats LB, Dill LM. 1998. The scent of death: chemosensory assessment of predation risk by prey animals. Ecoscience. 5(3):361-394.

Krause J, Ruxton GD, Ruxton GD, Ruxton IG. 2002. Living in groups. Oxford University Press.

Lanham EJ, Bull CM. 2004. Enhanced vigilance in groups in Egernia stokesii, a lizard with stable social aggregations. J Zool. 263(1):95-99.

Le Galliard J, Paquet M, Mugabo M. 2015. An experimental test of density- dependent selection on temperament traits of activity, boldness and sociability. J Evol Biol. 28(5):1144-1155.

Lê S, Josse J, Husson F. 2008. FactoMineR: an R package for multivariate analysis. J Stat Softw. 25(1):1-18.

Leimar O, McNamara JM. 2015. The evolution of transgenerational integration of information in heterogeneous environments. Am Nat. 185(3):E55-E69.

Léna J, De Fraipont M, Clobert J. 2000. Affinity towards maternal odour and offspring dispersal in the common lizard. Ecol Let. 3(4):300-308.

Léna J-P, Clobert J, De Fraipont M, Lecomte J, Guyot G. 1998. The relative influence of density and kinship on dispersal in the common lizard. Behav Ecol. 9(5):500-507.

Lima SL. 1998. Stress and decision making under the risk of predation: recent developments from behavioral, reproductive, and ecological perspectives. In: Advances in the Study of Behavior. Vol. 27. Elsevier. p. 215-290.

Lima SL. 2002. Putting predators back into behavioral predator-prey interactions. Trends Ecol Evol. 17(2):70-75.

Lima SL, Dill LM. 1990. Behavioral decisions made under the risk of predation: a review and prospectus. Canadian journal of zoology. 68(4):619-640. 
Lind J, Cresswell W. 2005. Determining the fitness consequences of antipredation behavior. Behav Ecol. 16(5):945-956.

López P, Aragón P, Martin J. 1998. Iberian rock lizards (Lacerta monticola cyreni) assess conspecific information using composite signals from faecal pellets. Ethology, 104(10), 809-820.

Love OP, Williams TD. 2008. The adaptive value of stress-induced phenotypes: effects of maternally derived corticosterone on sex-biased investment, cost of reproduction, and maternal fitness. Am Nat. 172(4):E135-E149.

Lüdecke D, Lüdecke MD. 2017. Package 'sjstats'.

Martín J, Civantos E, Amo L, López P. 2007. Chemical ornaments of male lizards Psammodromus algirus may reveal their parasite load and health state to females. Behav Ecol Sociobiol. 62(2):173-179.

Martín J, Lopez P. 2010. Condition-dependent pheromone signaling by male rock lizards: more oily scents are more attractive. Chem Senses. 35(4):253-262.

Martín J, López P. 2014. Pheromones and chemical communication in lizards. In: Reproductive biology and phylogeny of lizards and tuatara. Rheubert, Justin L., Dustin S. Siegel, and Stanley E. Trauth, eds. CRC Press. p. 43-77.

Mason RT, Parker MR. 2010. Social behavior and pheromonal communication in reptiles. J Comp Physiol A. 196(10):729-749.

Massot M, Lecomte J, Clobert J. 1992. Sex identification in juveniles of Lacerta vivipara. Amphib-Reptil. 13(1):21-25.

McCollum SA, Van Buskirk J. 1996. Costs and benefits of a predator- induced polyphenism in the gray treefrog Hyla chrysoscelis. Evolution. 50(2):583-593.

McNamara JM, Dall SR, Hammerstein P, Leimar O. 2016. Detection vs. selection: integration of genetic, epigenetic and environmental cues in fluctuating environments. Ecol Lett. 19(10):1267-1276. 
Mell H, Josserand R, Decencière B, Artacho P, Meylan S, Le Galliard J-F. 2016. Do personalities co-vary with metabolic expenditure and glucocorticoid stress response in adult lizards? Behav ecol and sociobiol. 70(6):951-961.

Meylan S, Belliure J, Clobert J, de Fraipont M. 2002 Stress and body condition as prenatal and postnatal determinants of dispersal in the common lizard (Lacerta vivipara). Horm Behav. 42: 319-326.

Meylan S., Clobert J. 2005. Is corticosterone-mediated phenotype development adaptive? Maternal corticosterone treatment enhances survival in male lizards. Horm. Behav. 48: $44-52$.

Moreira PL, López P, Martín J. 2008. Discrimination of conspecific faecal chemicals and spatial decisions in juvenile Iberian rock lizards (Lacerta monticola). acta ethologica, 11(1): 26-33.Nesse RM. 2005. Natural selection and the regulation of defenses: A signal detection analysis of the smoke detector principle. Evol hum behav. 26(1):88105.

Nettle D, Bateson M. 2015. Adaptive developmental plasticity: what is it, how can we recognize it and when can it evolve? Proc R Soc B. 282(1812):20151005.

Oksanen J, Kindt R, Legendre P, O’Hara B, Stevens MHH, Oksanen MJ, Suggests M. 2007. The vegan package. Community ecology package. 10:631-637.

Ortega Z, Mencía A, Pérez-Mellado V. 2017. Rapid acquisition of antipredatory responses to new predators by an insular lizard. Behav Ecol and Sociobiol. 71(1):1.

Potticary A, Duckworth RA. 2020. Multiple environmental stressors induce an adaptive maternal effect. Am Nat. 196(4): 487-500.

Ripley B, Venables B, Bates DM, Hornik K, Gebhardt A, Firth D, Ripley MB. 2013. Package 'mass'. Cran R, 538.

Rodríguez-Prieto I, Martín J, Fernández-Juricic E. 2011. Individual variation in behavioural plasticity: direct and indirect effects of boldness, exploration and sociability on 
habituation to predators in lizards. Proc R Soc B. 278(1703):266-273.

Sheriff MJ, Bell A, Boonstra R, Dantzer B, Lavergne SG, McGhee KE, MacLeod KJ, Winandy L, Zimmer C, Love OP. 2017. Integrating ecological and evolutionary context in the study of maternal stress. Integr Comp Biol. 57(3):437-449.

Sheriff MJ, Krebs CJ, Boonstra R. 2010. The ghosts of predators past: population cycles and the role of maternal effects under fluctuating predation risk. Ecology. 91: 2983-2994.

Sheriff MJ, Love OP. 2013. Determining the adaptive potential of maternal stress. Ecol lett. 16(2):271-280.

Shine R, Downes SJ. 1999. Can pregnant lizards adjust their offspring phenotypes to environmental conditions? Oecologia. 119(1):1-8.

Stamps JA, Krishnan V. 2014. Combining information from ancestors and personal experiences to predict individual differences in developmental trajectories. Am Nat. 184(5):647-657.

Stein LR, Bukhari SA, Bell AM. 2018. Personal and transgenerational cues are nonadditive at the phenotypic and molecular level. Nature ecology \& evolution. 2(8):1306-1311.

Teyssier A, Bestion E, Richard M, Cote J. 2014. Partners' personality types and mate preferences: predation risk matters. Behav Ecol. 25(4):723-733.

Uller T. 2008. Developmental plasticity and the evolution of parental effects. Trends Ecol Evol. 23(8):432-438.

Van Damme R, Bauwens D, Thoen C, Vanderstighelen D, Verheyen R. 1995. Responses of naive lizards to predator chemical cues. J Herpetol.:38-43.

Webster M, Laland K. 2008. Social learning strategies and predation risk: minnows copy only when using private information would be costly. Proc R Soc B. 275(1653):2869-2876.

Wickham H, Chang W, Wickham MH. 2016. Package 'ggplot2'. Create Elegant Data Visualisations Using the Grammar of Graphics Version. 2(1):1-189.

Winandy L, Cote J. 2020. Data from: Maternal and personal information mediates the use of 
social cues about predation risk. Behav Ecol. Dryad, Dataset,

734 https://doi.org/10.5061/dryad.tdz08kpzf

735 Winandy L, Darnet E, Denoël M. 2015. Amphibians forgo aquatic life in response to alien 736 fish introduction. Anim Behav. 109:209-216.

737 
TABLE 1 Summary results of LMM model relating the effect of the different sources of 739 information (i.e. maternal, personal and social) and their interaction on lizard attraction to 740 conspecific cues. Significant effects are highlighted in bold.

\begin{tabular}{llllll}
\hline Paramaters: & Estimates & SE & $X^{2}{ }_{1}$ & $95 \%$ CI & p-value
\end{tabular}

Source of information

\begin{tabular}{lccccc}
\hline Maternal & 0.472 & 0.479 & 2.001 & $-0.447,1.391$ & 0.157 \\
Personal & 1.297 & 0.515 & 1.795 & $0.303,2.286$ & 0.180 \\
Social & 0.868 & 0.463 & 0.420 & $-0.022,1.758$ & 0.517 \\
Maternal * Personal & -0.791 & 0.702 & 0.379 & $-2.128,0.587$ & 0.538 \\
Maternal * Social & -0.500 & 0.674 & 0.947 & $-1.792,0.797$ & 0.330 \\
Personal * Social & -2.192 & 0.708 & 4.709 & $-3.544,-0.821$ & $\mathbf{0 . 0 3 0}$ \\
Maternal * Personal * Social & 2.255 & 1.020 & 4.886 & $0.225,4.214$ & $\mathbf{0 . 0 2 7}$
\end{tabular}

741

742

743

744

745

746

747

748

749

750 
751 TABLE 2 Summary results of LMM models relating the effect of personal and social 752 information about predation risk on lizard sociability in presence $(\mathrm{M}+)$ and absence $(\mathrm{M}-)$ of 753 maternal information about predation. Significant effects are highlighted in bold.

\begin{tabular}{llccccc}
\hline Maternal & Paramaters: & Estimates & SE & $X^{2}{ }_{1}$ & $95 \%$ CI & p-value \\
information & Source of information & & & & & \\
\hline M- & Personal & 1.217 & 0.546 & 0.222 & $0.164,2.269$ & 0.637 \\
& Social & 0.859 & 0.515 & 0.025 & $-0.138,1.853$ & 0.875 \\
& Personal * Social & -2.121 & 0.782 & 7.357 & $-3.630,-0.613$ & $\mathbf{0 . 0 0 7}$ \\
& & & & & & \\
M+ & Personal & 0.528 & 0.463 & 2.383 & $-0.367,1.428$ & 0.123 \\
& Social & 0.365 & 0.445 & 1.269 & $-0.491,1.251$ & 0.260 \\
& Personal * Social & -0.000 & 0.657 & 0.000 & $-1.389,1.308$ & 0.999 \\
& & & & & & \\
\hline
\end{tabular}


756 SUPPLEMENTARY TABLE 1 Linear discriminant analysis on the occurrence of chemical

757 compounds in samples from lizards exposed $(\mathrm{P}+)$ and unexposed to predation $(\mathrm{P}-)$ using the

758 LEfSe platform (http://huttenhower.sph.harvard.edu/galaxy/).These compounds were selected

759 using linear discriminant scores (LDA > 2.0) and Mann-Whitney test (p_MW = p-value, $\mathrm{p}<$ $760 \quad 0.05)$.

\begin{tabular}{lccrr}
\hline Chemical compounds & \multicolumn{2}{c}{$\begin{array}{l}\text { Occurrence in } \\
\text { treatment }(\%)\end{array}$} & \multirow{2}{*}{$\begin{array}{c}\text { LDA effect } \\
\text { size }(\log 10)\end{array}$} & p-value \\
\cline { 2 - 3 } & $\mathrm{P}+$ & $\mathrm{P}-$ & & \\
\hline X154 (Comp_1_Occ) & 16.67 & 66.67 & 4.4179 & $\mathbf{0 . 0 2 6}$ \\
X167 (Comp_2_Occ) & 8.33 & 58.33 & 4.5312 & $\mathbf{0 . 0 1 2}$ \\
X82 & 100 & 91.67 & 4.5351 & $\mathbf{0 . 0 1 2}$ \\
\hline
\end{tabular}

761

762 
763 SUPPLEMENTARY TABLE 2 Similarity percentage analysis on the occurrence of 764 chemical compounds in samples from lizards exposed $(\mathrm{P}+)$ and unexposed to predation $(\mathrm{P}-)$.

765 The contribution of the compound to between-treatments dissimilarity and its standard 766 deviation (SD) are provided. P-values are obtained from a permutation test with 1000 767 permutations. The compounds with a contribution larger than 0.01 are shown.

\begin{tabular}{|c|c|c|c|c|c|}
\hline \multirow[t]{2}{*}{ Chemical compounds } & \multirow[t]{2}{*}{$\begin{array}{l}\text { Compound } \\
\text { contribution }\end{array}$} & \multirow[t]{2}{*}{$\begin{array}{l}\text { SD of the } \\
\text { contribution }\end{array}$} & \multicolumn{2}{|c|}{$\begin{array}{l}\text { Occurrence of } \\
\text { chemical } \\
\text { compounds }\end{array}$} & \multirow[t]{2}{*}{ p-value } \\
\hline & & & $\mathrm{P}+$ & $\mathrm{P}-$ & \\
\hline X154 (Comp_1_Occ) & 0.0214 & 0.0178 & 0.1667 & 0.6667 & 0.0060 \\
\hline X167 (Comp_2_Occ) & 0.0198 & 0.0181 & 0.0833 & 0.5833 & $\mathbf{0 . 0 0 3 0}$ \\
\hline X76 & 0.0175 & 0.0182 & 0.3333 & 0.5000 & 0.2697 \\
\hline $\mathrm{X} 47$ & 0.0174 & 0.0181 & 0.5000 & 0.8333 & 0.1968 \\
\hline X109 & 0.0173 & 0.0179 & 0.5000 & 0.3333 & 0.6713 \\
\hline $\mathrm{X} 50$ & 0.0171 & 0.0177 & 0.3333 & 0.5000 & 0.5125 \\
\hline X159 & 0.0170 & 0.0176 & 0.0833 & 0.5000 & 0.0400 \\
\hline X80 & 0.0169 & 0.0179 & 0.4167 & 0.4167 & 0.9980 \\
\hline X168 & 0.0168 & 0.0185 & 0.4167 & 0.6667 & 0.9930 \\
\hline X137 & 0.0166 & 0.0183 & 0.0833 & 0.3333 & 0.9970 \\
\hline X152 & 0.0163 & 0.0184 & 0.5833 & 0.7500 & 0.6833 \\
\hline X170 & 0.0156 & 0.0181 & 0.3333 & 0.3333 & 0.9970 \\
\hline X101 & 0.0153 & 0.0178 & 0.1667 & 0.4167 & 0.3137 \\
\hline X106 & 0.0152 & 0.0175 & 0.3333 & 0.3333 & 1.0000 \\
\hline X79 & 0.0151 & 0.0168 & 0.2500 & 0.4167 & 0.5964 \\
\hline X126 & 0.0150 & 0.0173 & 0.3333 & 0.3333 & 0.9970 \\
\hline X66 & 0.0146 & 0.0178 & 0.3333 & 0.2500 & 0.9970 \\
\hline X249 & 0.0142 & 0.0173 & 0.3333 & 0.2500 & 1.0000 \\
\hline X149 & 0.0142 & 0.0172 & 0.3333 & 0.2500 & 0.9990 \\
\hline X145 & 0.0135 & 0.0174 & 0.1667 & 0.3333 & 0.2448 \\
\hline X235 & 0.0127 & 0.0165 & 0.1667 & 0.3333 & 0.2757 \\
\hline X116 & 0.0111 & 0.0160 & 0.1667 & 0.2500 & 0.6034 \\
\hline X21 & 0.0110 & 0.0160 & 0.1667 & 0.2500 & 0.4645 \\
\hline X100 & 0.0105 & 0.0151 & 0.1667 & 0.2500 & 0.3386 \\
\hline
\end{tabular}


SUPPLEMENTARY TABLE 3 The part of each compound on the LDA axis was analyzed

771 with a linear model with LDA axis as a dependent variable and the occurrence of the

772 compounds ass an explanatory variable. Significant ones are highlighted in bold.

\begin{tabular}{|c|c|c|c|c|c|}
\hline Compounds & $\begin{array}{c}\text { Std } \\
\text { coefficients }\end{array}$ & $\begin{array}{c}\text { CI } \\
\text { lower }\end{array}$ & $\begin{array}{c}\text { CI } \\
\text { upper }\end{array}$ & t-test & p-value \\
\hline $\mathrm{X} 10$ & -0.0549 & -1.6208 & 1.5110 & -0.0727 & 0.9427 \\
\hline X100 & 0.0246 & -1.0412 & 1.0903 & 0.0478 & 0.9623 \\
\hline X101 & -0.5980 & -1.5129 & 0.3168 & -1.3557 & 0.1889 \\
\hline X103 & 0.9287 & -0.5825 & 2.4400 & 1.2745 & 0.2158 \\
\hline X104 & 1.3901 & -0.0503 & 2.8305 & 2.0014 & 0.0578 \\
\hline X105 & 0.0172 & -1.5489 & 1.5832 & 0.0227 & 0.9821 \\
\hline X106 & -0.0161 & -0.9342 & 0.9021 & -0.0363 & 0.9714 \\
\hline X109 & 0.3089 & -0.5584 & 1.1762 & 0.7386 & 0.4679 \\
\hline X113 & -1.3837 & -2.5407 & -0.2267 & -2.4802 & 0.0213 \\
\hline X116 & -0.5115 & -1.5530 & 0.5301 & -1.0184 & 0.3196 \\
\hline $\mathrm{X} 12$ & -1.0491 & -3.1649 & 1.0668 & -1.0283 & 0.3150 \\
\hline X126 & 0.1074 & -0.8096 & 1.0243 & 0.2428 & 0.8104 \\
\hline X130 & -1.0517 & -3.1673 & 1.0639 & -1.0309 & 0.3138 \\
\hline X137 & -0.1343 & -1.0264 & 0.7579 & -0.3121 & 0.7579 \\
\hline X142 & 1.1128 & -0.3740 & 2.5996 & 1.5522 & 0.1349 \\
\hline $\mathrm{X} 145$ & -0.3440 & -1.3320 & 0.6440 & -0.7221 & 0.4779 \\
\hline X149 & 0.4039 & -0.5315 & 1.3393 & 0.8955 & 0.3802 \\
\hline $\mathrm{X} 15$ & 0.2747 & -1.0285 & 1.5778 & 0.4371 & 0.6663 \\
\hline $\mathrm{X} 152$ & -0.4032 & -1.3039 & 0.4975 & -0.9284 & 0.3633 \\
\hline X154 comp_1 & -0.9819 & -1.7450 & -0.2187 & -2.6683 & 0.0140 \\
\hline X158 & -1.3174 & -2.4894 & -0.1454 & -2.3311 & 0.0293 \\
\hline X159 & -0.9936 & -1.8385 & -0.1487 & -2.4388 & 0.0233 \\
\hline X164 & -1.4314 & -2.8639 & 0.0010 & -2.0724 & 0.0502 \\
\hline X165 & -1.2787 & -3.3697 & 0.8123 & -1.2682 & 0.2180 \\
\hline X167 comp_2 & -1.2037 & -1.9519 & -0.4555 & -3.3364 & 0.0030 \\
\hline X168 & 0.2310 & -0.6573 & 1.1192 & 0.5393 & 0.5951 \\
\hline $\mathrm{X} 170$ & 0.1876 & -0.7268 & 1.1021 & 0.4255 & 0.6746 \\
\hline X173 & -1.0790 & -2.2977 & 0.1398 & -1.8360 & 0.0799 \\
\hline X18 & -0.3930 & -1.6902 & 0.9042 & -0.6283 & 0.5363 \\
\hline X180 & 1.5318 & -0.5256 & 3.5893 & 1.5441 & 0.1368 \\
\hline X188 & -0.8465 & -2.3672 & 0.6741 & -1.1545 & 0.2607 \\
\hline X192 & -0.8847 & -3.0152 & 1.2458 & -0.8612 & 0.3984 \\
\hline X198 & 0.7797 & -1.3588 & 2.9182 & 0.7562 & 0.4576 \\
\hline $\mathrm{X} 20$ & -0.3384 & -1.4902 & 0.8133 & -0.6094 & 0.5485 \\
\hline $\mathrm{X} 21$ & -0.3416 & -1.3967 & 0.7134 & -0.6715 & 0.5089 \\
\hline X217 & -0.8847 & -3.0152 & 1.2458 & -0.8612 & 0.3984 \\
\hline X218 & -1.1271 & -3.2351 & 0.9809 & -1.1088 & 0.2795 \\
\hline X235 & -0.5819 & -1.5478 & 0.3840 & -1.2494 & 0.2247 \\
\hline X236 & -1.1271 & -3.2351 & 0.9809 & -1.1088 & 0.2795 \\
\hline
\end{tabular}




\begin{tabular}{lrrrrr}
\hline X249 & 0.2264 & -0.7206 & 1.1734 & 0.4959 & 0.6249 \\
X254 & -1.1271 & -3.2351 & 0.9809 & -1.1088 & 0.2795 \\
X287 & 1.0433 & -1.0731 & 3.1597 & 1.0224 & 0.3177 \\
X290 & 1.0433 & -1.0731 & 3.1597 & 1.0224 & 0.3177 \\
X38 & -1.0491 & -3.1649 & 1.0668 & -1.0283 & 0.3150 \\
X41 & -1.0517 & -3.1673 & 1.0639 & -1.0309 & 0.3138 \\
X47 & -0.6549 & -1.5262 & 0.2164 & -1.5587 & 0.1333 \\
X5 & -1.0491 & -3.1649 & 1.0668 & -1.0283 & 0.3150 \\
X50 & -0.3397 & -1.2047 & 0.5253 & -0.8144 & 0.4241 \\
X51 & -0.2165 & -1.7796 & 1.3467 & -0.2872 & 0.7766 \\
X6 & -1.0491 & -3.1649 & 1.0668 & -1.0283 & 0.3150 \\
X63 & 0.6205 & -1.5282 & 2.7691 & 0.5989 & 0.5554 \\
X66 & 0.2890 & -0.6547 & 1.2326 & 0.6351 & 0.5319 \\
X69 & -1.3283 & -2.7800 & 0.1235 & -1.8974 & 0.0710 \\
X70 & -1.4324 & -3.5038 & 0.6391 & -1.4341 & 0.1656 \\
X72 & 0.2352 & -1.0694 & 1.5399 & 0.3739 & 0.7121 \\
X76 & -0.4189 & -1.2771 & 0.4393 & -1.0124 & 0.3223 \\
X79 & -0.4978 & -1.3893 & 0.3936 & -1.1582 & 0.2592 \\
X80 & -0.1599 & -1.0350 & 0.7153 & -0.3788 & 0.7084 \\
X81 & -1.1271 & -3.2351 & 0.9809 & -1.1088 & 0.2795 \\
X82 & 1.1938 & -0.9070 & 3.2946 & 1.1785 & 0.2512 \\
X93 & 0.4390 & -0.8553 & 1.7333 & 0.7034 & 0.4892 \\
\hline
\end{tabular}

774 
SUPPLEMENTARY TABLE 4 Contributions (in \%) of the chemical compound to the first

777 two axis of the MCA (MC1 and MC2).

\begin{tabular}{|c|c|c|c|c|c|}
\hline Compounds & $\mathrm{MC1}$ & MC2 & Compounds & $\mathrm{MC1}$ & MC2 \\
\hline X10_N & 0.08707947 & 0.00676785 & X192_N & 0.00118471 & 0.0001665 \\
\hline X10_Y & 0.95787414 & 0.07444634 & X192_Y & 0.02724844 & 0.00382942 \\
\hline X100_N & 0.61839521 & 0.61958591 & X198_N & 0.06461066 & 0.00456372 \\
\hline X100_Y & 2.3499018 & 2.35442644 & X198_Y & 1.48604528 & 0.1049655 \\
\hline X101_N & 0.22311634 & 1.30143302 & X20_N & 0.29363092 & 0.1629909 \\
\hline X101_Y & 0.54185396 & 3.16062306 & X20_Y & 0.05872618 & 0.03259818 \\
\hline X103_N & 0.056515 & 0.00701668 & X21_N & 0.46876316 & 0.32609739 \\
\hline X103_Y & 0.62166501 & 0.07718348 & X21_Y & 1.78130002 & 1.23917008 \\
\hline X104_N & 0.17645263 & 0.00402807 & X217_N & 0.00118471 & 0.0001665 \\
\hline X104_Y & 1.94097893 & 0.04430879 & X217_Y & 0.02724844 & 0.00382942 \\
\hline X105_N & 0.06249526 & 0.25844474 & X218_N & 0.02872433 & 0.00087635 \\
\hline X105_Y & 0.6874479 & 2.84289219 & X218_Y & 0.66065968 & 0.02015609 \\
\hline X106_N & 0.42805431 & 0.37976616 & X235_N & 1.80156004 & 0.37562457 \\
\hline X106_Y & 0.85610862 & 0.75953231 & X235_Y & 5.40468012 & 1.12687372 \\
\hline X109_N & 0.04200149 & 0.89777594 & X236_N & 0.02872433 & 0.00087635 \\
\hline X109_Y & 0.05880208 & 1.25688632 & X236_Y & 0.66065968 & 0.02015609 \\
\hline X110_Y & $6.27 \mathrm{E}-31$ & $6.28 \mathrm{E}-31$ & X249_N & 1.4466928 & 0.04811525 \\
\hline X113_N & 0.4497757 & 0.31876193 & X249_Y & 3.5133 & 0.11685132 \\
\hline X113_Y & 3.14842993 & 2.23133348 & X254_N & 0.02872433 & 0.00087635 \\
\hline X116_N & 0.77109756 & 0.42683848 & X254_Y & 0.66065968 & 0.02015609 \\
\hline X116_Y & 2.93017074 & 1.62198623 & X287_N & 0.04602633 & 0.00108232 \\
\hline X12_N & 0.01123698 & 0.28539565 & X287_Y & 1.05860561 & 0.02489335 \\
\hline X12_Y & 0.25845049 & 6.56409996 & X290_N & 0.04602633 & 0.00108232 \\
\hline X126_N & 0.19141592 & 0.19835902 & X290_Y & 1.05860561 & 0.02489335 \\
\hline X126_Y & 0.38283184 & 0.39671804 & X38_N & 0.01123698 & 0.28539565 \\
\hline X130_N & 0.01419281 & 0.00128481 & X38_Y & 0.25845049 & 6.56409996 \\
\hline X130_Y & 0.32643459 & 0.02955061 & X41_N & 0.01419281 & 0.00128481 \\
\hline X137_N & 0.49408083 & 0.562244 & X41_Y & 0.32643459 & 0.02955061 \\
\hline X137_Y & 0.2964485 & 0.3373464 & X47_N & 0.41674108 & 0.00247901 \\
\hline X142_N & 0.01048617 & 6.8491E-07 & X47_Y & 0.20837054 & 0.00123951 \\
\hline X142_Y & 0.11534788 & 7.534E-06 & X5_N & 0.01123698 & 0.28539565 \\
\hline X145_N & 1.17781216 & 0.53612855 & $\mathrm{X} 5 \_\mathrm{Y}$ & 0.25845049 & 6.56409996 \\
\hline X145_Y & 3.53343648 & 1.60838564 & X50_N & 0.78277465 & 0.55263318 \\
\hline X149_N & 0.4678568 & 1.43284687 & X50_Y & 1.09588451 & 0.77368645 \\
\hline X149_Y & 1.13622366 & 3.47977097 & X51_N & 0.00685812 & 0.06098394 \\
\hline X15_N & 0.62093225 & 0.18748768 & X51_Y & 0.07543933 & 0.67082337 \\
\hline X15_Y & 4.34652574 & 1.31241374 & X6_N & 0.01123698 & 0.28539565 \\
\hline X152_N & 0.39781619 & 0.13244647 & X6_Y & 0.25845049 & 6.56409996 \\
\hline X152_Y & 0.19890809 & 0.06622324 & X63_N & 0.0009896 & 0.02512299 \\
\hline X154_N & 0.62926464 & 1.18887168 & X63_Y & 0.02276076 & 0.57782867 \\
\hline X154_Y & 0.88097049 & 1.66442035 & X66_N & 0.04275621 & 1.154135 \\
\hline X158_N & 0.01699763 & 0.30022806 & X66_Y & 0.10383651 & 2.80289928 \\
\hline
\end{tabular}




\begin{tabular}{llllll} 
X158_Y & 0.11898339 & 2.10159644 & X69_N & 0.08117691 & 0.30164285 \\
X159_N & 0.02426734 & 1.18142499 & X69_Y & 0.89294599 & 3.31807137 \\
X159_Y & 0.05893497 & 2.86917497 & X70_N & 0.14127656 & 0.14549519 \\
X164_N & 0.28453983 & 0.34604872 & X70_Y & 3.24936079 & 3.34638926 \\
X164_Y & 3.12993813 & 3.80653593 & X72_N & 0.05224178 & 0.06001557 \\
X165_N & 0.02725379 & 0.00853318 & X72_Y & 0.36569249 & 0.42010901 \\
X165_Y & 0.62683718 & 0.19626309 & X76_N & 1.03119579 & 0.13375063 \\
X167_N & 1.46431053 & 0.74432017 & X76_Y & 1.44367411 & 0.18725088 \\
X167_Y & 2.92862107 & 1.48864034 & X79_N & 0.47481352 & 0.00225228 \\
X168_N & 3.32261458 & 0.70066263 & X79_Y & 0.94962704 & 0.00450456 \\
X168_Y & 5.53769097 & 1.16777104 & X80_N & 0.31288219 & 0.76759627 \\
X170_N & 2.70165226 & 0.72427865 & X80_Y & 0.43803506 & 1.07463478 \\
X170_Y & 5.40330452 & 1.44855729 & X81_N & 0.02872433 & 0.00087635 \\
X173_N & 0.07106418 & 0.0537883 & X81_Y & 0.66065968 & 0.02015609 \\
X173_Y & 0.49744925 & 0.37651812 & X82_N & 0.68990226 & 0.69607478 \\
X18_N & 0.40058147 & 0.03872462 & X82_Y & 0.02999575 & 0.03026412 \\
X18_Y & 2.80407032 & 0.27107234 & X93_N & 0.04384443 & 0.12851646 \\
X180_N & 0.0015009 & 0.04406517 & X93_Y & 0.306911 & 0.8996152 \\
X180_Y & 0.03452076 & 1.01349892 & & & \\
X188_N & 2.10212683 & 0.08341418 & & & \\
X188_Y & 0.19110244 & 0.00758311 & & & \\
\hline & & & & &
\end{tabular}

778

779

780 
781 SUPPLEMENTARY TABLE 5 Linear discriminant analysis on the abundance of chemical 782 compounds in samples from lizards exposed $(\mathrm{P}+)$ and unexposed to predation (P-) using the 783 LEfSe platform (http://huttenhower.sph.harvard.edu/galaxy/). These compounds were selected 784 using linear discriminant scores (LDA > 2.0) and Mann-Whitney test ( $7850.05)$.

\begin{tabular}{lccrrr}
\hline Chemical compounds & \multicolumn{2}{c}{$\begin{array}{c}\text { Predation } \\
\text { treatment }\end{array}$} & \multirow{2}{*}{$\begin{array}{l}\text { LDA effect } \\
\text { size }(\log 10)\end{array}$} & p-value \\
\cline { 2 - 3 } & P+ & P- & & \\
\hline X154 (Comp_1_Ab) & 0.0053 & 0.0197 & 4.0560 & $\mathbf{0 . 0 1 7}$ \\
X167 (Comp_2_Ab) & 0.0061 & 0.0161 & 3.8549 & $\mathbf{0 . 0 2 1}$ \\
\hline
\end{tabular}

786

787 
highlighted in bold.

\begin{tabular}{|c|c|c|c|c|c|}
\hline Compounds & Spearman & p-value & Compounds & Spearman & p-value \\
\hline $\mathrm{X} 10$ & -0.05530165 & 0.79744512 & $\mathrm{X} 188$ & -0.10697978 & 0.61880429 \\
\hline X100 & 0.03061097 & 0.88708807 & X192 & 91967 & 0.28846596 \\
\hline X101 & -0.15480506 & 0.47012651 & X198 & 0.16567443 & 0.43912168 \\
\hline X103 & 0.34178232 & 0.10212057 & $\mathrm{X} 20$ & -0.16209189 & 0.44921815 \\
\hline X104 & 0.349035 & 0.09458715 & $\mathrm{X} 21$ & -0.0599975 & 0.78063901 \\
\hline X105 & 0.02085144 & 0.92295847 & X217 & -0.22591967 & 0.28846596 \\
\hline X106 & 0.16888698 & 0.43017202 & $\mathrm{X} 218$ & -0.19579705 & 0.35918525 \\
\hline X109 & 0.19611882 & 0.35838041 & $\mathrm{X} 235$ & -0.23776087 & 0.26325008 \\
\hline X110 & 0.26347826 & 0.21267378 & $\mathrm{X} 236$ & -0.19579705 & 0.35918525 \\
\hline X113 & -0.53701651 & 0.00681334 & X249 & 0.10284253 & 0.6325087 \\
\hline X116 & -0.01224439 & 0.95471671 & $\mathrm{X} 254$ & -0.19579705 & 0.35918525 \\
\hline $\mathrm{X} 12$ & -0.16567443 & 0.43912168 & $\mathrm{X} 287$ & 0.22591967 & 0.28846596 \\
\hline X126 & -0.12329786 & 0.56597757 & X290 & 0.22591967 & 0.28846596 \\
\hline X130 & -0.25604229 & 0.22718485 & X38 & -0.16567443 & 0.43912168 \\
\hline X137 & 0.09914272 & 0.64486447 & $\mathrm{X} 41$ & -0.25604229 & 0.22718485 \\
\hline X142 & 0.22936586 & 0.28097636 & $\mathrm{X} 47$ & -0.06688491 & 0.75616286 \\
\hline X145 & -0.0240047 & 0.91 & $X 5$ & 567443 & 0.43912168 \\
\hline X149 & 0.10825529 & 0.61460371 & X50 & -0.05388413 & 0.80253589 \\
\hline $\mathrm{X} 15$ & 0.09530152 & 0.65778959 & X51 & 0.05167531 & 0.81048395 \\
\hline $\mathrm{X} 152$ & 0.02790562 & 0.89701279 & X6 & -0.16567443 & 0.43912168 \\
\hline X154 Comp_1 & -0.5058312 & 0.01167671 & X63 & 0.07530656 & 0.72654294 \\
\hline X158 & -0.31010812 & 0.14027926 & X66 & 0.01623829 & 0.93996884 \\
\hline X159 & -0.33450885 & 0.11011241 & X69 & -0.34178232 & 0.10212057 \\
\hline X164 & -0.45510537 & 0.0254441 & X70 & -0.34641016 & 0.09726418 \\
\hline X165 & -0.07530656 & 0.72654294 & $\mathrm{X} 72$ & 0.23749744 & 0.26379515 \\
\hline X167 Comp_2 & -0.6201157 & 0.00122749 & X76 & -0.11310813 & 0.5987301 \\
\hline X168 & 0.20294927 & 0.34154524 & X79 & -0.16681475 & 0.4359336 \\
\hline $\mathrm{X} 170$ & 0.16629669 & 0.43738043 & X80 & 0.14806 & 0.4899164 \\
\hline $\mathrm{X} 173$ & -0.32977352 & 0.11555654 & X81 & -0.19579705 & 0.35918525 \\
\hline X18 & -0.12706869 & 0.55406363 & X82 & 0.28869565 & 0.17085682 \\
\hline X180 & 0.31628754 & 0.132136 & X93 & 0.16639948 & 0.43709315 \\
\hline
\end{tabular}


792

793

794

795 (PC1 and PC2).

\begin{tabular}{lrrrrr}
\hline Compounds & PC1 & PC2 & Compounds & PC1 & PC2 \\
\hline X10 & 0.1959 & 0.4768 & X188 & 0.6677 & 0.0001 \\
X100 & 0.0491 & 0.5664 & X192 & 0.123 & 0.2168 \\
X101 & -0.381 & -0.2837 & X198 & 0.183 & 0.6085 \\
X103 & 0.0343 & -0.07 & X20 & 0.1801 & 0.6261 \\
X104 & -0.2463 & -0.1697 & X21 & 0.2124 & 0.569 \\
X105 & -0.2229 & -0.0075 & X217 & 0.123 & 0.2168 \\
X106 & 0.7676 & -0.2997 & X218 & 0.0189 & 0.5303 \\
X109 & 0.7751 & -0.4438 & X235 & 0.1235 & 0.806 \\
X110 & 0.6277 & -0.3355 & X236 & 0.0189 & 0.5303 \\
X113 & -0.2754 & 0.0022 & X249 & 0.4427 & 0.504 \\
X116 & -0.3169 & -0.2341 & X254 & 0.0189 & 0.5303 \\
X12 & 0.4433 & -0.3345 & X287 & -0.2208 & -0.05 \\
X126 & -0.526 & -0.0445 & X290 & -0.2208 & -0.05 \\
X130 & -0.1643 & 0.0017 & X38 & 0.4433 & -0.3345 \\
X137 & 0.5267 & -0.3332 & X41 & -0.1643 & 0.0017 \\
X142 & -0.2309 & -0.0219 & X47 & 0.5296 & -0.1133 \\
X145 & -0.352 & -0.291 & X5 & 0.4433 & -0.3345 \\
X149 & 0.5456 & -0.123 & X50 & 0.5747 & -0.1144 \\
X15 & 0.2367 & 0.5367 & X51 & 0.1185 & 0.5611 \\
X152 & -0.2564 & -0.2697 & X6 & 0.4433 & -0.3345 \\
X154 & 0.0732 & 0.4958 & X63 & -0.1231 & -0.0353 \\
X158 & -0.1944 & -0.1423 & X66 & 0.5769 & -0.1836 \\
X159 & 0.317 & -0.0973 & X69 & -0.1761 & -0.1599 \\
X164 & -0.2274 & 0.0014 & X70 & -0.1541 & 0.0114 \\
X165 & -0.1578 & -0.0667 & X72 & 0.3652 & -0.1774 \\
X167 & 0.2211 & 0.6519 & X76 & 0.5691 & 0.3097 \\
X168 & -0.4313 & -0.3386 & X79 & 0.5326 & -0.3433 \\
X170 & -0.4382 & -0.3218 & X80 & 0.4533 & 0.1594 \\
X173 & 0.0827 & 0.0813 & X81 & 0.0189 & 0.5303 \\
X18 & 0.4734 & -0.2247 & X82 & 0.7766 & -0.0192 \\
X180 & 0.3983 & -0.1893 & X93 & -0.3158 & -0.05
\end{tabular}
compound observed from principal components analyses: Correlations between the 62 different compounds identified in the samples compound and the first two axis of the PCA 
799 SUPPLEMENTARY TABLE 8 Effect of the indicators of chemical composition on lizard 800 sociability: the number of compounds, the two axis of the MCA on the abundance (i.e., MC1 801 and MC2) and the LDA first axis of the occurrence. We analyzed the triple interaction with 802 maternal and personal information to extract effects sizes and compare it to the effect size of 803 the treatment. Significance is only reported for information and should not be used to compare 804 the strength of effects.

\begin{tabular}{lccc}
\hline \multirow{2}{*}{$\begin{array}{c}\text { Indicators of chemical } \\
\text { composition }\end{array}$} & \multicolumn{3}{c}{$\begin{array}{c}\text { Interactive effect with maternal and } \\
\text { personal information }\end{array}$} \\
\cline { 2 - 4 } & sdt. estimate & $\chi_{1}^{2}$ & p-value \\
\hline Number of compounds & -0.48 & 1.619 & 0.203 \\
MC1 occurrence & -0.15 & 3.081 & 0.081 \\
MC2 occurrence & -0.11 & 1.195 & 0.274 \\
LDA occurrence & 0.19 & 5.623 & 0.018 \\
Comp_1_Occ & -0.396 & 4.001 & 0.046 \\
Comp_2_Occ & -0.622 & 9.248 & 0.002 \\
\hline
\end{tabular}

805

806 
807 SUPPLEMENTARY TABLE 9 Effect of the indicators of chemical composition on lizard

808 sociability: the number of compounds, the two axis of the PCA on the abundance (i.e., PC1

809 and PC2) and the LDA first axis of the abundance. We analyzed the triple interaction with

810 maternal and personal information to extract effects sizes and compare it to the effect size of

811 the treatment. Significance is only reported for information and should not be used to compare

812 the strength of effects.

813

\begin{tabular}{lccc}
\hline $\begin{array}{c}\text { Indicators of chemical } \\
\text { composition }\end{array}$ & \multicolumn{3}{c}{$\begin{array}{c}\text { Interactive effect with maternal and } \\
\text { personal information }\end{array}$} \\
\cline { 2 - 4 } & sdt. estimate & $\chi^{2}{ }_{1}$ & p-value \\
\hline PC1 abundance & -0.250 & 2.742 & 0.098 \\
PC2 abundance & -0.484 & 10.886 & 0.001 \\
LDA abundance & 0.532 & 3.638 & 0.056 \\
Comp_1_Ab & -0.820 & 11.034 & 0.001 \\
Comp_2_Ab & -0.596 & 8.125 & 0.004 \\
\hline
\end{tabular}

814 
817 The predation treatment (light grey and dark red for respectively unexposed and exposed to 818 predation cues) was manipulated in each of the three source of information following a full819 crossed experimental design. Half of the gravid mother were exposed to predation risk (i.e., 820 maternal information). After hatching, each clutch was divided in halves and raised with or 821 without predation risk (i.e., personal information) in order to have all combination of treatment between mothers and offspring: offspring unexposed from mother unexposed (P-M$823, \mathrm{n}=39$; $\mathrm{P}$ for personal information and $\mathrm{M}$ for maternal information), offspring unexposed 824 from mother exposed (P-M+, n=36), offspring exposed from mother unexposed (P+M-, $\mathrm{n}=30)$ 825 and offspring exposed from mother exposed $(\mathrm{P}+\mathrm{M}+, \mathrm{n}=32)$. The social information was 826 provided by cues from conspecific (using feces) that were either previously exposed (S+), or unexposed (S-) to predation risk.

\section{SOURCE OF INFORMATION}

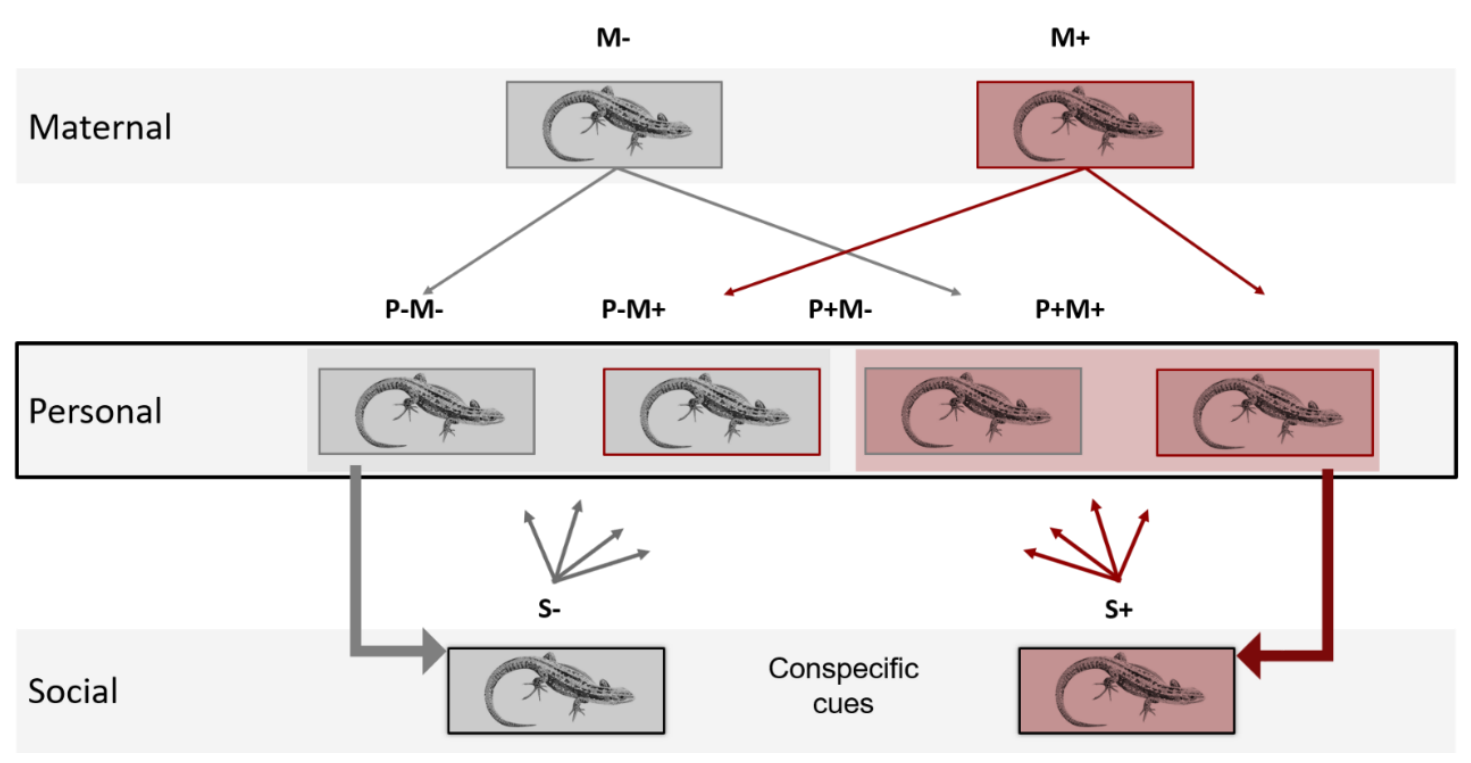



lizard social attraction.

832 The variation of social attraction (mean $\pm \mathrm{SE}$ ) according to the interaction between personal 833 and social information depended on the maternal information about predation: a) in the 834 absence of maternal information about predation risk (M-), there is a significant interaction 835 between personal information ( $\mathrm{P}$ - versus $\mathrm{P}+$ ) and social information ( $\mathrm{S}-$, light grey bars and $836 \mathrm{~S}+$, dark red bars); b) in the presence of maternal information about predation risk $(\mathrm{M}+)$, there 837 is a slight increase of sociability when the number of sources of information about the actual risk of predation increased. See results for statistics.

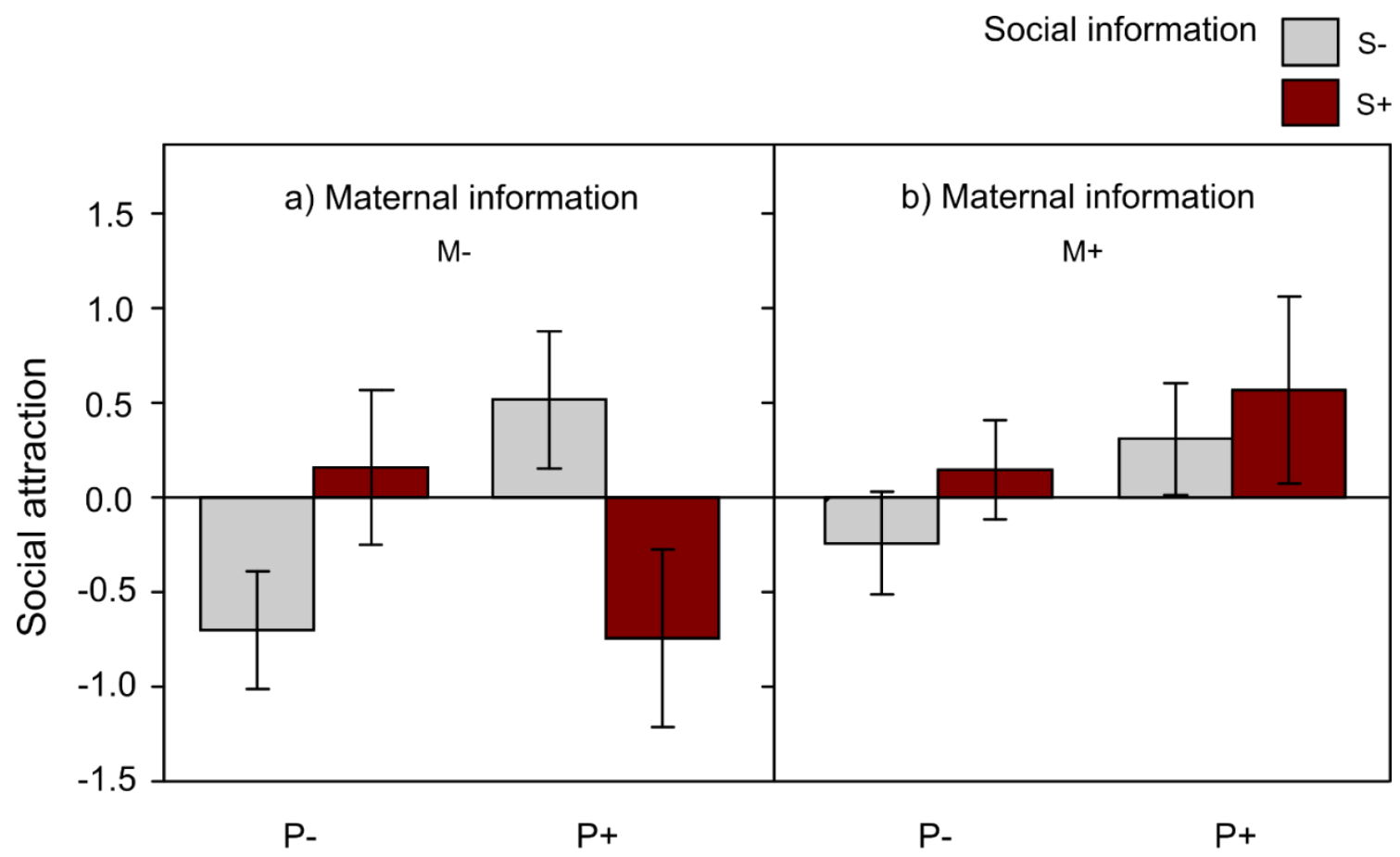



sociability

843 Comparison of effect size $(95 \% \mathrm{CI})$ of the triple interaction between maternal information, 844 personal information and social information ( $\mathrm{S}$ - versus $\mathrm{S}+$ ) and the triple interaction between 845 maternal information, personal information and the different indicators of chemical 846 composition on lizard sociability. The indicators of chemical composition are the number of 847 compounds, the two axis of the MCA on the occurrence (i.e., MC1 and MC2), the LDA first 848 axis of the occurrence and the occurrence of two compounds: Comp_1_Occ and 849 Comp_2_Occ.

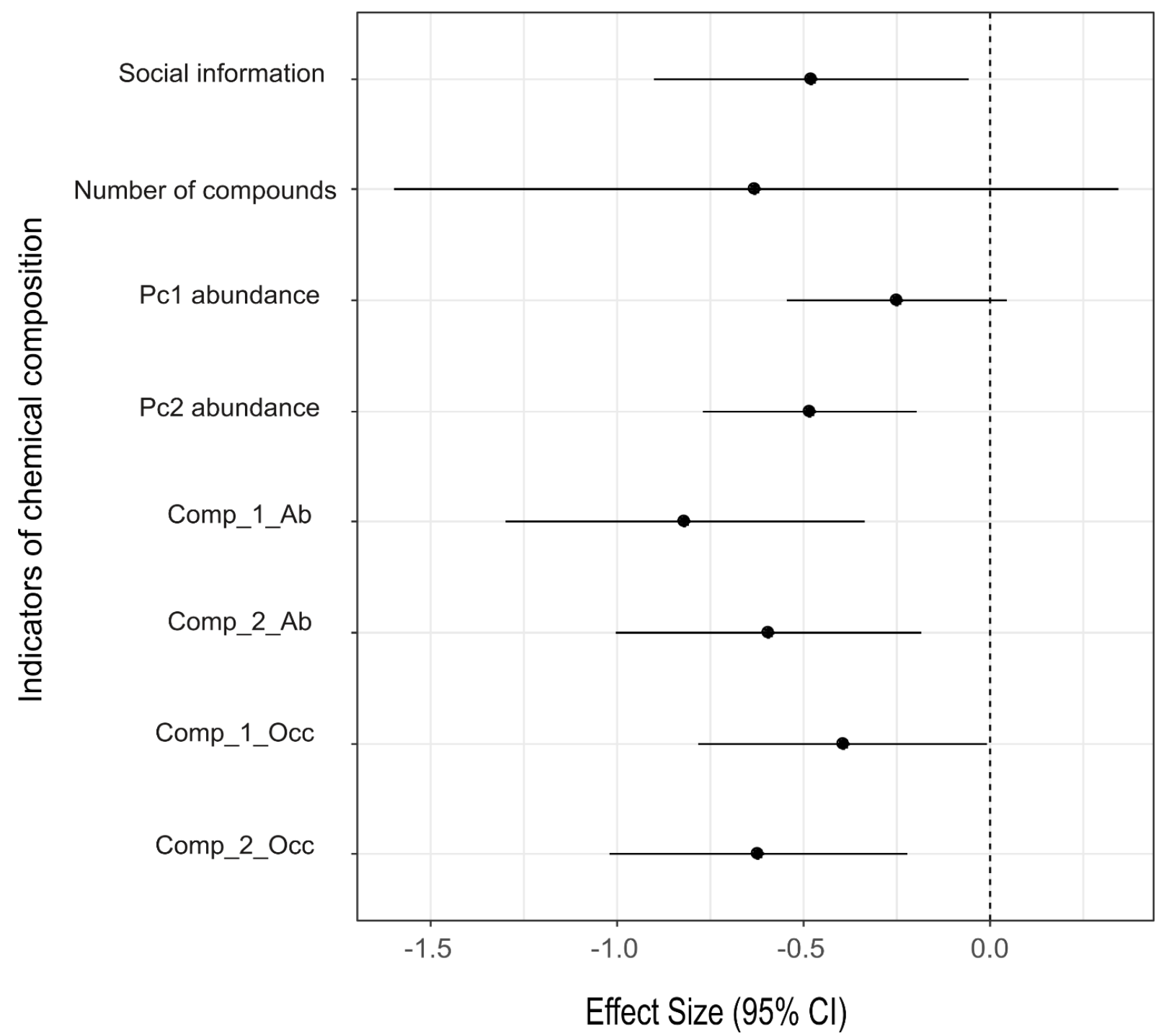



composition on lizard sociability

854

855

856

857

Comparison of effect size $(95 \% \mathrm{CI})$ of the triple interaction between maternal information, personal information and social information (S-versus $\mathrm{S}+$ ) and the triple interaction between maternal information, personal information and the different indicators of chemical composition on lizard sociability. The indicators of chemical composition are the number of compounds, the two axis of the PCA on the abundance (i.e., PC1 and PC2), the LDA first axis of the abundance and the abundance of two compounds: Comp_1_Ab and Comp_2_Ab.

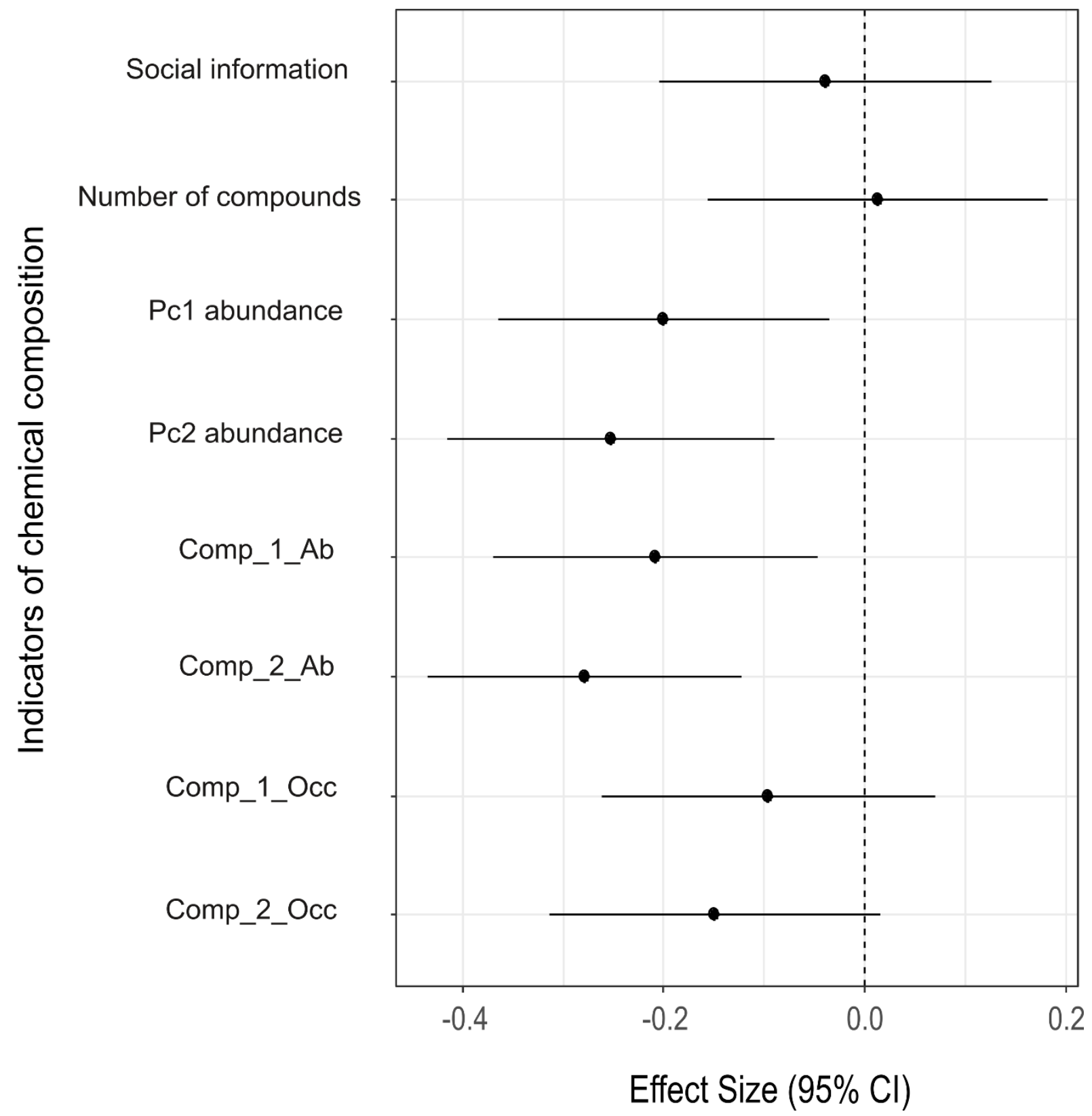

